\author{
DESENVOLVIMENTO E PRODUTIVIDADE DO \\ GERGELIM EM FUNÇÃO DA ADUBAÇÃO FOSFA- \\ TADA E USO DE BACTÉRIAS CONDICIONADORAS
}

\title{
DEVELOPMENT AND PRODUCTIVITY OF SESAME AS A FUNCTION OF PHOSPHATE FERTILIZATION AND USE OF CONDITIONING BACTERIA
}

\author{
Nailson dos Santos Lopes ${ }^{1}$ \\ Green Biotech Brasil ${ }^{2}$ \\ Kevin Theo Gentil ${ }^{3}$
}

\begin{abstract}
Resumo: O gergelim (Sesa- que ocorra um aumento demamum indicum L.) é uma cultura siado na exploração de recursos de grande importância devido não renováveis como no caso do ao seu grande potencial econô- fósforo. $\mathrm{O}$ presente trabalho teve mico e sua utilização em diver- como objetivo avaliar o desensos setores como a gastronomia, volvimento e a produtividade do cosméticos, medicamentos, bio- gergelim submetido a diferentes combustíveis, entre outros. Com doses de fósforo, mantendo-se isso faz-se necessário à busca constante as adubações nitrogede alternativas que possibilite o nadas e potássicas, além de avaaumento na sua produção sem liar o efeito da inoculação das
\end{abstract}

1 Engenheiro Agronômo pela Universidade Federal do Cariri

2 Empresa de biotecnologia

3 Cientista CEO da Green Biotech Brasil, Inventor e Coletor da Tecnologia Barvar no Brasil

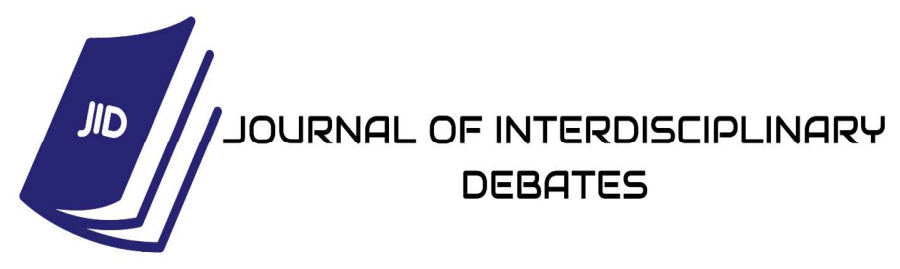


Vol. 02 - n 04 - ano 2021

Editora Acadêmica Periodicojs

sementes com bactérias do gênero Pseudomonas. $\mathrm{O}$ experimento foi conduzido no Sítio Madeira Cortada, situado na zona rural de Missão Velha-CE. O solo da área experimental é classificado como Latossolo Vermelho Amarelo típico. O experimento foi realizado em delineamento em blocos casualizados em esquema de parcela subdividida, com três repetições. As parcelas foram compostas por quatro doses de fósforo $(0,25,50$ e $100 \%$ da dose recomendada) e as subparcelas ao uso do produto inoculante da marca PhosphoBarvar-2 ou BARVAR P (com e sem), totalizando assim 24 observações. Cada parcela media três metros de largura por três metros de comprimento, totalizando $9 \mathrm{~m}^{2}$. Os dados passaram pela análise de variância (ANOVA) e pelo teste $\mathrm{F}$ e submetidos ao teste de regressão polinomial determinando-se a curva de resposta de cada variável. O programa utilizado para analisar os dados foi o SISVAR, sendo avaliado as seguintes variáveis: altura de planta, diâmetro do colmo, comprimento da vagem, $n^{0}$ de vagem/planta, $n^{0}$ de grãos/planta, massa de 1000 grãos, produtividade de vagens, produtividade de grãos e rendimento. A interação adubação e PhosphoBarvar não apresentou diferenças para as variáveis. A adubação apresentou diferença significativa a 5 \% para o diâmetro do colmo e comprimento da vagem e significativo a $1 \%$ para o $\mathrm{n}^{\mathrm{o}}$ de vagem/planta, produtividade de vagem e produtividade de grãos. O PhosphoBarvar não apresentou diferença significativa para as variáveis $n^{0}$ de grãos por vagem, massa de 1000 grãos, e rendimento. Nas demais variáveis, apresentou diferença significativa a 5\%. Portanto observou-

\section{ND}


ISSN: 2675-469X

Vol. 02 - n 04 - ano 2021

Editora Acadêmica Periodicojs

-se que a adubação fosfatada e a

utilização da bactéria trouxeram

benefícios para a produção do

gergelim sendo a bactéria res-

ponsável por um aumento de 278

$\mathrm{kg} \mathrm{ha}^{-1}$ e $143 \mathrm{~kg} \mathrm{ha}^{-1}$ na produti-

vidade de vagem e produtividade

de grãos respectivamente, sendo

necessário a realização de outros

trabalhos para que ocorra a com-

provação dos benefícios dos tratamentos aplicados.

Palavras-chave: Sesamum indicum L. Produtividade. Adubação biológica. PhosphoBarvar-2.

\begin{abstract}
The sesame (Sesamum indicum L.) is a crop of great importance due to its great economic potential and its use in various sectors such as gastronomy, cosmetics, medicines, biofuels, among others. Thus, it is necessary to search for alternatives that allow for an increase
\end{abstract}

in production without an excessive increase in the exploitation of non-renewable resources such as in the case of phosphorus. This study aimed to evaluate the development and productivity of sesame subjected to different doses of phosphorus, keeping nitrogen and potassium fertilization constant, in addition to evaluating the effect of seed inoculation with bacteria of the genus Pseudomonas. The experiment was carried out at Sítio Madeira Cortada, located in the rural area of Missão Velha-CE. The soil in the experimental area is classified as a typical Red Yellow Latosol. The experiment was carried out in a randomized block design in a split-plot scheme, with three replications. The plots were composed of four phosphorus doses $(0,25,50$ and $100 \%$ of the recommended dose) and the subplots used the inoculant pro- 
ISSN: 2675-469X

Vol. 02 - n 04 - ano 2021

Editora Acadêmica Periodicojs

duct PhosphoBarvar-2 or BARVAR P (with and without), thus totaling 24 observations. Each plot measured three meters wide by three meters long, totaling 9 $\mathrm{m} 2$. The data underwent analysis of variance (ANOVA) and the $\mathrm{F}$ test and were submitted to the polynomial regression test, determining the response curve for each variable. The program used to analyze the data was SISVAR, and the following variables were evaluated: plant height, stem diameter, pod length, pod/plant number, grain/plant number, 1000 grain mass, pod yield, grain yield and yield. The interaction between fertilization and PhosphoBarvar did not show differences for the variables. Fertilization showed a significant difference at $5 \%$ for stalk diameter and pod length and a significant difference at $1 \%$ for number of pod/plant, pod yield and grain yield. Phos-
phoBarvar did not show significant difference for the variables number of grains per pod, mass of 1000 grains, and yield. In the other variables, there was a significant difference at $5 \%$. Therefore, it was observed that phosphate fertilization and the use of bacteria brought benefits to sesame production, the bacteria being responsible for an increase of $278 \mathrm{~kg} \mathrm{ha}^{-1}$ and $143 \mathrm{~kg} \mathrm{ha}^{-1}$ in pod yield and grain yield, respectively. It is necessary to carry out other work so that the benefits of the applied treatments can be proven.

Keywords: Sesamum indicum

L. Productivity. Biological fertilization. PhosphoBarvar-2.

\section{INTRODUÇÃO}

O gergelim (Sesamum indicum L.) é uma planta olea-

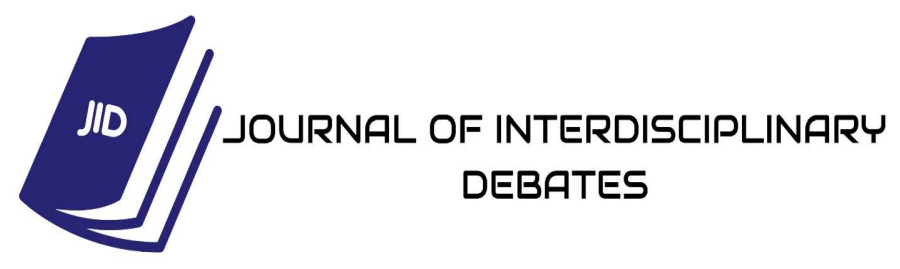


ISSN: 2675-469X

Vol. 02 - n 04 - ano 2021

Editora Acadêmica Periodicojs

ginosa originária da África e da Ásia de onde se disseminou para vários países. Há muitos séculos essa planta vem sendo cultivada na Índia, seu cultivo também se estende em países como o Japão, Turquia, China, Egito e até nas Américas. Foi introduzida no século XVI, pelos portugueses no Brasil (BELTRÃO e VIEIRA, 2001).

Responsável por menos de $0,5 \%$ da área cultivada $\mathrm{e}$ da produção em âmbito mundial de gergelim, o Brasil no período de 2001 a 2010 passou de 15 mil para 16 mil toneladas em relação a produção, e sua área colhida foi de 24 mil para 25 mil hectares. $\mathrm{O}$ rendimento médio da cultura, nesse mesmo período, passou de 625 para 640 quilos de grãos por hectares, sendo esta produção basicamente vinda de pequenos e médios produtores que utilizam a mão de obra familiar dos estados de Goiás, Minas Gerais, São Pau-

lo, Mato Grosso, Bahia, Pernambuco, Ceará, Piauí, Paraíba e Rio Grande do Norte. O Brasil em 2011, tinha 8 mil hectares plantados produziu 5 mil toneladas de grãos, atingindo uma produtividade de $625 \mathrm{Kg}$ de grãos por hectares (FAO, 2012; KOURI; ARRIEL, 2009).

Contribuindo com $67 \%$ da produção nacional, o estado de Goiás é o principal produtor de gergelim do Brasil. Além de Goiás, são produtores de gergelim os estados de Mato Grosso, Mato grosso do Sul, Minas Gerais, Rio Grande do Norte, Ceará, Paraíba, Piauí, Bahia e Pernambuco (EMBRAPA, 2014).

O gergelim é cultivado basicamente para produção de óleo, fazendo com que essa cultura tenha grande importância econômica e social, uma vez que a qualidade do óleo é superior às

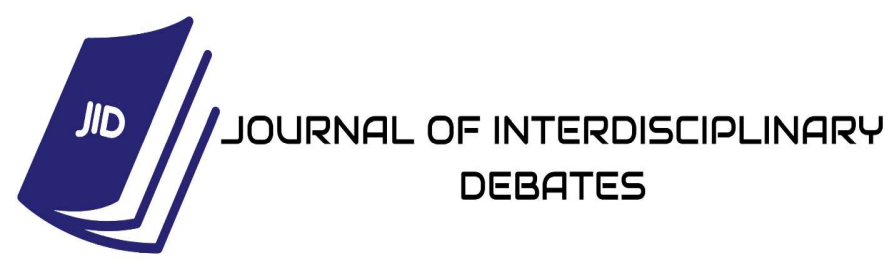


Vol. 02 - n 04 - ano 2021

Editora Acadêmica Periodicojs

demais oleaginosas comumen- suprir a demanda nutricional das te utilizadas para alimentação plantas. Porém, esses insumos humana (LAYANEZ- GARSA- podem causar, quando aplicados BALL; MÉNDEZ-NATERA, de maneira incorreta, problemas 2006). ao meio ambiente, aumentar os

A farinha do gergelim é outro produto oriundo do grão dessa oleaginosa, sendo fonte de vitaminas $\mathrm{A}, \mathrm{B}, \mathrm{C}$ e possuem bom teor de ferro, cálcio e fósforo (BELTRÃO et al., 1989).

O gergelim na região Nordeste, apresenta-se como uma alternativa de renda e fonte de proteína para os pequenos e médios produtores visto que essa oleaginosa faz parte do consumo popular dessas classes de baixa rendas, servindo como alternativa para diminuir o agravante quadro de carência alimentar dessa população (BELTRÃO e VIEIRA, 2001).

A atual produção agrícola faz uso intenso de insumos industrializados com o intuito de custos da produção, além de inibir o potencial e as oportunidades oferecidas pela exploração dos componentes biológicos do solo em benefício da produção sustentável. Com o intuito do aumento da produtividade e a diminuição nos custos da produção para o produtor, tem sido estudada alternativas para a redução do uso de fertilizantes químicos (RATZ, 2014; SOUZA \& PERES,2016).

Atuando com potencialidade direto ou indiretamente no solo ou nas plantas os bioestimulantes tem sido grandes alternativas de uso, pois esses aumentam a produtividade e a qualidade, pulsionam resistência à planta $\mathrm{e}$ promovem o crescimento e proteção das plantas, uma vez que

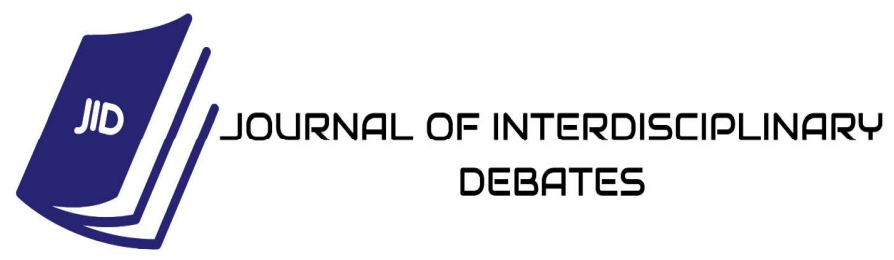


ISSN: $2675-469 X$

Vol. 02 - n 04 - ano 2021

Editora Acadêmica Periodicojs

seus princípios e agentes orgânicos não contém substâncias agrotóxicas. No setor agrícola onde esses produtos vêm sendo utilizados ocorre os benefícios como o equilíbrio nutricional e a preservação das interações biológicas, onde o ambiente é favorável ao desenvolvimento dos microrganismos benéficos do solo, proporcionam maior eficiência nutricional e fotossintética das plantas (SOUZA e PERES, 2016).

Além de proporcionar maior desenvolvimento das plantas, aumentar a resistência em relação ao ataque de pragas e patógenos, a aplicação de bioestimulantes agem diretamente sobre fitoparasitas devido a presença de substancias tóxicas (MARCILIO et al., 2014).

Sabendo disto, o objetivo desse trabalho avaliar o desenvolvimento e a produtividade do gergelim em relação a aplica- ção da adubação fosfatada, como também avaliar o efeito da inoculação de bactérias do gênero Pseudomonas e Pantoea agglomerans (PhosphoBarvar-2) ou (BARVAR P) nas sementes e no solo. Esse produto por causa de sua composição, agentes biológicos que exercem a função de solubilizadores, perlita e água pode ser enquadrado em diferentes classes de fertilizantes no Brasil, como condicionador de solo biológico, fertilizante orgânico composto e inoculante, além da classe internacional biofertilizante.

\section{REVISÃO DE LITERATURA}

\section{Gergelim}

\section{Classificação e Características}

O gergelim (Sesamum indicum L.) pertence à família Pedaliácea, das quais são iden- 
ISSN: $2675-469 \mathrm{X}$

Vol. 02 - n 04 - ano 2021

Editora Acadêmica Periodicojs

tificados 14 gêneros no mundo. feriores de plantas adultas e são O gênero Sesamum, que é cons- lanceoladas na parte superior. tituído de 49 espécies, é o mais As flores são completas e axilaimportante e sendo o S.indicum res, variando em número de $1 \mathrm{a}$ L. o mais cultivado (MAZZANI, 3 por axila foliar, possuem colo1983).

No continente Africano se encontra a maioria das espécies do gênero Sesamum na forma silvestre, sendo este considerado o continente de origem. $\mathrm{Na}$ Ásia por sua vez, apresenta maior variedade de espécies cultivadas. O gergelim apresenta grande diversidade nas características morfológicas, podendo variar na altura, entre 0,50 a $3,00 \mathrm{~m}$, com caule ereto apresentando ou não ramificações e pêlos, com sistema radicular pivotante.

As folhas por sua vez são introduzidas no caule nas posições alternadas ou opostas, apresentando-se de forma mais largas e irregularmente dentadas ou lombadas nas partes inração variável de lilás ao róseo, e são gamopétalas (flor em que as pétalas são soldadas entre si), zigomorfas (flor com simetria bilateral que pode ser dividida em duas partes iguais), tubulares, bilabiadas, com o lábio inferior mais alongado (BELTRÃO e VIEIRA, 2001).

O fruto caracteriza-se por ser uma cápsula pilosa e dependendo da variedade pode ser deiscente ou indeiscente, ter comprimento variando de 2 a 8 $\mathrm{cm}$, o número de loculos variando em pares de 4, 6, 8 ou 10 e a sua quantidade de 1 a 3 na mesma planta ou em cada axila. As sementes são pequenas, achatadas, de coloração variando de preto ao branco. O peso de 1000

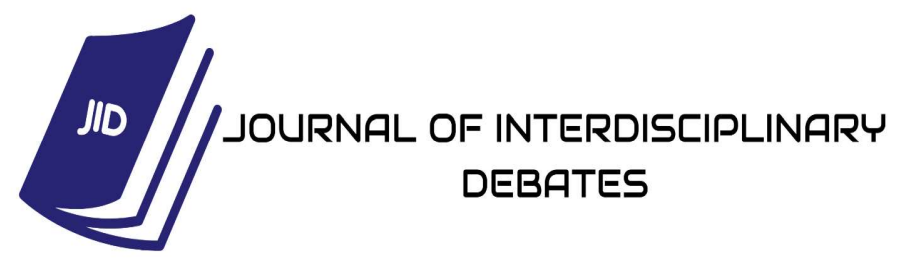


ISSN: $2675-469 \mathrm{X}$

Vol. 02 - n 04 - ano 2021

Editora Acadêmica Periodicojs

sementes atinge o valor de 2 a 4

$\mathrm{g}$, de acordo com a cultivar e o

ambiente da cultura (BELTRÃO e VIEIRA, 2001).

Considerada o principal produto da cultura, as cultivares que apresentam sementes de coloração branco e creme possuem maior valor comercial, pois as sementes de cores escuras restringem-se ao uso caseiro e medicinal (SILVA, 2006).

Características do cultivar BRS Seda

A cultivar foi obtida através da seleção massal para sementes de coloração branca aplicada na cultivar Zirra FAO 51284. A planta caracteriza por possuir porte médio de $1,55 \mathrm{~m}$, ciclo de 90 dias superando a precocidade do cultivar CNPA G4. O crescimento da planta é ramificado com hastes de coloração ver- de, após 36 dias da germinação ocorre o início do florescimento sendo sua floração e maturação uniformes. Apresenta apenas um fruto por axila, sendo estes deiscentes que se abrem após a maturação completa. As sementes possuem coloração branca, um teor de óleo superior a $52 \%$, peso médio de mil sementes de 3,22 g, podendo-se com isso atribuir um maior valor comercial, principalmente para as indústrias de alimento e confeitarias (EMBRAPA, 2007).

A cultivar de gergelim BRS Seda tem potencial para produzir até $2500 \mathrm{~kg} \mathrm{ha}^{-1}$ de sementes em condições ideais de cultivo, se adapta bem em áreas com temperaturas médias entre 23 e $30{ }^{\circ} \mathrm{C}$, com altitudes de até $1.250 \mathrm{~m}$ e precipitações entre 300 a $850 \mathrm{~mm}$ anuais bem distribuídas, e é tolerante às doenças da mancha angular, cercosporiose 
ISSN: 2675-469X

Vol. 02 - n 04 - ano 2021

Editora Acadêmica Periodicojs

e à murcha de Macrophomina,. (EMBRAPA, 2007).

É indicada para o cultivo na região Nordeste, Cerrados de Goiás, Mato Grosso, Distrito Federal, São Paulo e região norte fluminense. Pois, seu rendimento máximo pode ser obtido com precipitações bem distribuídas variando entre 500 e $600 \mathrm{~mm}$; e com taxas de $35 \%$ da germinação ao florescimento, $45 \%$ durante o florescimento e $20 \%$ com o início da maturação dos frutos (EMBRAPA, 2007).

\section{Importância econômica}

O cultivo do gergelim sofre poucas alterações em termos de área plantada e produção no Brasil. A essa problemática pode ser atribuída fatores como pouco acesso a informações de mercado pelos produtores, falta de políticas de incentivo à pro- dução, problemas relacionados com a comercialização e problemas climáticos, principalmente na região Nordeste (EMBRAPA, 2014).

Porém, com os preços praticados do gergelim nos últimos anos no mercado nacional e internacional, configura-se como excelente alternativa a exploração da cultura. Dados da Organização das Nações Unidas para Agricultura e Alimentação (FAO), cerca de $30 \%$ da produção obtida no Brasil é exportada mundialmente. $\mathrm{O}$ valor médio da tonelada do gergelim exportado em 2009 foi de US\$1.240,86, já o valor médio do produto médio importado foi de US\$ 1.393,01. Os principais países importadores do gergelim são China, Japão, Turquia, Coreia, Estados Unidos, Grécia, Israel, Alemanha, Arábia Saudita e Egito. Entre os anos de 2006 a 2009, ocorreu um aumen-

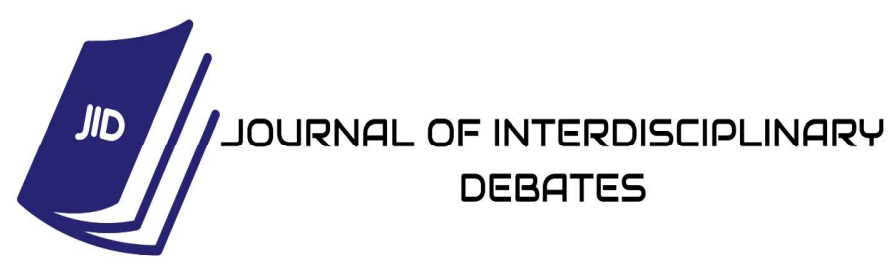


ISSN: 2675-469X

Vol. 02 - n 04 - ano 2021

Editora Acadêmica Periodicojs

to de $50 \%$ em relação ao valor da tonelada comercializada mundialmente. Aproximadamente $90 \%$ do gergelim mundialmente produzido é destinado ao consumo alimentício. Os grãos são utilizados de diversas formas na indústria alimentícia, destacando a indústria de panificação ou com a comercialização do óleo extraído para utilização na culinária. No ano de 2009, o gergelim brasileiro destacou-se no mercado internacional, com o preço de exportação no valor de US\$ 2.684,21 a tonelada (FAO, 2012; KOURI; ARRIEL, 2009).

Com as novas tecnologias de cultivo à disposição dos agricultores é crescente o interesse no plantio do gergelim em grade escala nas regiões Centro-Oeste, Sul e Sudeste, sendo esta uma cultura alternativa para diversificar a produção agrícola. Pois a mesma, pode ser utiliza- da em cultivo rotacional com as culturas do milho, algodão, soja e também, como cultivo de segunda safra (EMBRAPA, 2014).

Conforme Langham;

Wiemers (2002), a demanda mundial de produtos que leva em sua composição o gergelim cresceu $550 \%$, nos últimos 40 anos. Portanto, torna-se uma excelente oportunidade para fonte de renda a exploração da cultura nas regiões Centro-Sul e no Semiárido brasileiro.

\section{Exigências nutricionais e ma-} nejo da adubação do gergelim

O gergelim extrai do solo quantidades elevadas de nitrogênio $(\mathrm{N})$ e de potássio $(\mathrm{k})$ podendo variar de acordo com o estado nutricional da planta, volume da produção, variedade utilizada, assim como, da parte colhida da planta como apresentado

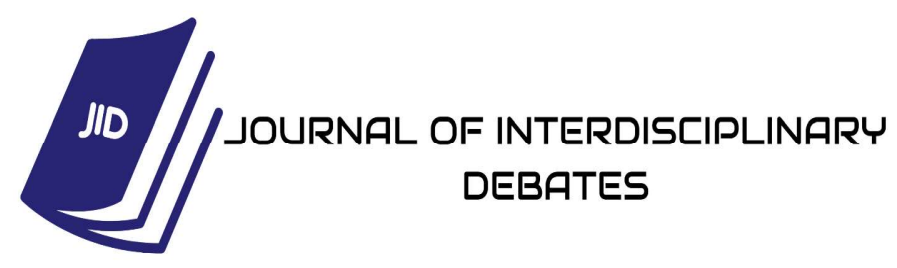


Vol. 02 - n 04 - ano 2021

Editora Acadêmica Periodicojs

na (Tabela 1). Em geral para produzir $1000 \mathrm{~kg} \mathrm{ha}^{-1}$ de sementes a planta precisa extrair do solo 50 $\mathrm{kg} \mathrm{ha}^{-1}$ de N, $14 \mathrm{~kg} \mathrm{ha}^{-1}$ de P2O5 e $60 \mathrm{~kg} \mathrm{ha}^{-1}$ de K2O. No final do cultivo cerca de $97 \%$ dos nutrientes do solo são extraídos pelas plantas, contendo nos frutos um percentual de 33 a $60 \%$ do NPK extraído (EMBRAPA,2007 b).

A planta absorve pouco
NPK no período entre o plantio até o trigésimo dia, passando esse período a exigência por esses nutrientes pela planta cresce e atinge a demanda máxima de nitrogênio aos 74 dias, de fósforo dos 60 aos 90 dias e de potássio depois do $35^{\circ}$ dia, crescendo até o final do ciclo (EMBRAPA,2007 b).

Tabela 1. Total de fitomassa e de nutrientes por órgão das plantas de gergelim na colheita

\begin{tabular}{|c|c|c|c|c|c|c|c|c|}
\hline \multirow{2}{*}{$\begin{array}{c}\text { Parte da } \\
\text { planta }\end{array}$} & \multicolumn{2}{|c|}{ Fitomassa } & \multicolumn{2}{|c|}{$\mathbf{N}$} & \multicolumn{2}{|c|}{$\overline{\mathbf{P}_{2} \mathbf{O}_{5}}$} & \multicolumn{2}{|c|}{$\mathrm{K}_{2} \mathrm{O}$} \\
\hline & $\mathrm{Kg} / \mathrm{ha}$ & $\%$ & Kg/ha & $\%$ & Kg/ha & $\%$ & Kg/ha & $\%$ \\
\hline Raízes & 779 & 7,7 & 2,84 & 2,4 & 0,95 & 3,0 & 4,33 & 3,2 \\
\hline Caules & 2.846 & 28,1 & 10,24 & 8,5 & 7,94 & 25,0 & 42,98 & 31,5 \\
\hline Folhas & 2.058 & 20,4 & 34,98 & 29,2 & 12,30 & 38,6 & 16,74 & 12,3 \\
\hline Frutos & 4.429 & 43,8 & 71,74 & 59,9 & 10,63 & 33,4 & 72,42 & 53,1 \\
\hline Total & 10.112 & $\overline{100,0}$ & 119,8 & 100,0 & 31,82 & 100,0 & 136,47 & $\overline{100,0}$ \\
\hline
\end{tabular}

Para alcançar altos ren- nitrogênio o responsável pelo fadimentos produtivos e econômi- tor crescimento da planta (COScos com a cultura do gergelim, TA et al., 2012). tornasse imprescritível o maPara solos que apresennejo adequado do potássio e do tar através de suas análises para nitrogênio, primeiro e segundo macronutrientes um teor de fóselementos mais exigidos pelas foro menor que $10 \mathrm{mg} \mathrm{dm}^{-3}(10$ plantas respectivamente, sendo ppm), teor de potássio menor que

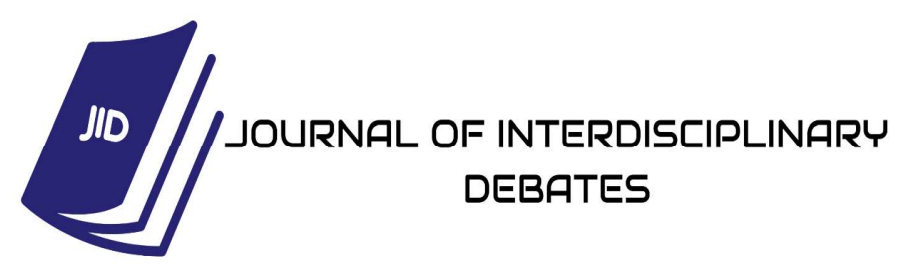


ISSN: $2675-469 X$

Vol. 02 - n 04 - ano 2021

Editora Acadêmica Periodicojs

$0,23 \mathrm{cmolc} \mathrm{dm}^{-3}$ e teor de matéria orgânica inferior a 2,6\%, será ne-

\section{Dinâmica no solo}

cessário fazer a correção do solo, com aplicação de fertilizantes levando-se em conta a textura do solo e a mobilidade dos nutrientes (EMBRAPA, 2014).

Para o fósforo, deve-se aproveitar o plantio e aplicar de uma só vez no solo devido a pouca mobilidade. O potássio por possuir mobilidade intermediária, sua aplicação pode ser no plantio ou em duas aplicações junto com o nitrogênio levando-se em conta a capacidade de lixiviação do solo. O nitrogênio por ter uma grande mobilidade no solo pode ser aplicado em duas vezes sendo a metade após o desbaste e a outra metade após 25 dias, usando preferencialmente o sulfato de amônio como fonte (BELTRÃO e VIEIRA, 2001).

Fósforo

O fósforo é um elemento que tem grande importância na produção agrícola, esse elemento compõe cerca de $0,12 \%$ da crosta terrestre. As reservas de fósforo na sua maioria podem ser encontradas em sedimentos marinhos, fosfatos inorgânicos dissolvidos nos oceanos, nos solos e em rochas que apresentam os minerais como a apatita na sua constituição. Apesar de existir outros minerais que contém o fósforo, somente as apatitas possuem teores significativos (STEVESON; COLE, 1999).

As rochas fosfáticas são as principais fontes de $\mathrm{P}$, estes recursos naturais não renováveis segundo estimativas se exaurirão nos próximos 80 a 100 anos se não tiverem seu uso racionalizado. Dos $75 \%$ de $\mathrm{P}$ que são

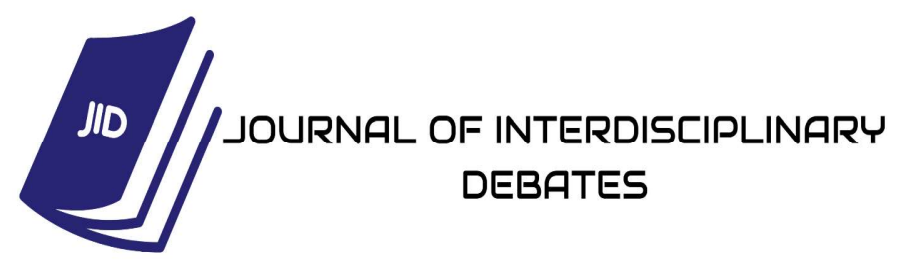


Vol. 02 - n 04 - ano 2021

Editora Acadêmica Periodicojs

aplicados e que de certa forma são perdidos ou ficam retidos nas partículas do solo, se pudesse ser disponibilizado para as plantas, a produção agrícola mundial seria suficientemente autossustentável por cerca de 100 anos (MOREIRA; SIQUEIRA, 2006).

O fósforo pode ser dividido em quatro categorias: na forma iônica e em compostos na solução do solo; adsorvidos na superfície dos constituintes minerais do solo; minerais cristalinos e amorfos; e componentes da matéria orgânica. Presente entre 0,2 e $5,0 \mathrm{~g} \mathrm{~kg}^{-1}$ apenas uma pequena fração desse teor total de fósforo está em forma disponível para as plantas (FERNANDES, 2006).

O fósforo se caracteriza por ser um nutriente pouco disponível na rizosfera, devido a fatores como sua interação com constituintes do solo; interação com o Al, Fe e Ca; ocorrência em formas orgânicas e sua lenta taxa de difusão na solução do solo (FERNANDES,2006).

O fósforo em seu processo de reciclagem no solo está fortemente relacionado através da matéria orgânica, com de outros elementos, vale ressaltar que o acúmulo de carbono, nitrogênio e enxofre é dependente do teor de $\mathrm{P}$, portanto, influenciará na fertilidade do solo (STEVENSON, 1986).

Em solos das regiões tropicais e subtropicais o $\mathrm{P}$ é o elemento menos frequente, esse fator limita a produção, em particular o das culturas anuais. No Brasil, encontram-se teores menores que $10 \mathrm{ppm}$ de fósforo disponível em 90\% das análises de solo feitas (MALAVOLTA, 1980).

Nos solos agrícolas brasileiros, o fósforo na sua maior 
ISSN: 2675-469X

Vol. 02 - n 04 - ano 2021

Editora Acadêmica Periodicojs

parte ocorre em solos ácidos na fração mineral ligada aos óxidos de ferro e alumínio, e nos solos neutros ou alcalinos nas frações ligados ao cálcio $(\mathrm{Ca})$. De acordo com o tipo de solo, o fósforo orgânico oscila entre 3-90\% do fósforo total, e na MOS (Matéria Orgânica do Solo) entre 1-3\% sendo encontrado principalmente na forma de fosfolipídios, nucleotídeos e fosfato de inositol. O fósforo do solo na sua maior parte está na fração não lábil e dificilmente se tornarão disponível para as plantas devido a sua forma quimicamente estável. A fração disponível para as plantas (fração lábil) representa menos que $5 \%$ do total (MOREIRA; SIQUEIRA, 2006).

A característica mais importante na definição de um solo como sendo fonte ou dreno de P é o seu teor da fração argila. $\mathrm{O}$ incremento do teor de argila em solos mais intemperizados é outro ponto de destaque, pois esses tendem a obter pouco ganho como fonte no solo, mas perdem muito como dreno. Esse fato justifica o porquê de solos pobres em P como do cerrado e com textura média entre 150 a $350 \mathrm{~kg} \mathrm{ha}^{-1}$ de argila, ou até mesmo os arenosos, nos quais são cultivadas culturas anuais tem-se mostrados mais produtivos que os argilosos (NOVAIS et al., 2007).

Para quantificar os teores de fósforo no solo, os métodos extratores utilizados no Brasil são o Melich-1 e Resina de Troca mista. Desenvolvido para solos pobres em $\mathrm{P}$ e intemperizados como os que predominam no país, o método Melich-1 é um extrator ácido. Já o método das resinas (simples ou mista) o embasamento é de que elas imitam a função das raízes, que a partir da fase sólida do solo adsorve o nu- 
ISSN: 2675-469X

Vol. 02 - n 04 - ano 2021

Editora Acadêmica Periodicojs

triente em solução e força o seu ressuprimento (VEGÜTZ; NOVAIS, 2015).

A necessidade do nutriente a fim de fornecer as condições ideais para a cultura que será implantada pode ser determinada através destes métodos, de acordo com os teores obtidos de fósforos esse nutriente é classificado nos níveis baixos, médio ou alto. Se a verificação for feita pelo método de Resina, deve-se classificar de acordo com a faixa de menor quantidade de argila (0$15 \%$ ), uma vez que esse método não apresenta sensibilidade ao poder tampão do solo. Uma vez classificada a fertilidade quanto ao nutriente, a dose recomendada deve ser determinada com base na produtividade esperada (VEGÜTZ; NOVAIS, 2015).

Na maior parte do Nordeste onde predomina solos com teor baixos de $\mathrm{P}$ disponível, reco- menda-se para a maioria das culturas aplicações anuais de manutenção nas doses de 20 a $50 \mathrm{~kg}$ ha-1 (RAIJ et al., 1982).

\section{Dinâmica na planta}

$\mathrm{A}$ atuação do $\mathrm{P}$ na cultura do gergelim é muito importante pois esse nutriente atua no processo de formação de diferentes órgãos da planta e participa de vários processos metabólicos, como a transferência de energia, síntese e estabilidade de membrana, síntese de ácidos nucléicos, glicose, respiração, ativação e desativação de enzimas, metabolismo de carboidratos, reações redox e fixação de $\mathrm{N}_{2}$ (FRANDOLOSO, 2006; VANCE et al. 2003). Para uma planta ter condições adequada de crescimento estima-se que ela deve possuir uma concentração em torno de

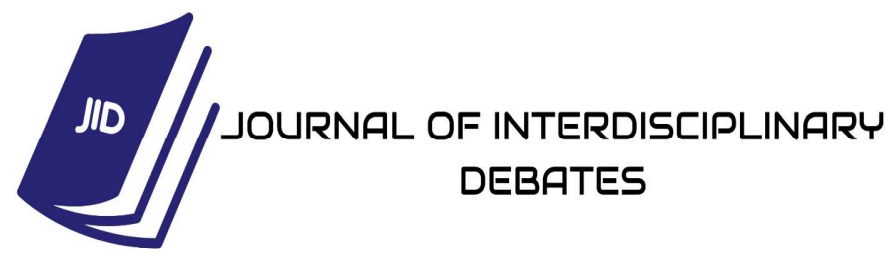


ISSN: 2675-469X

Vol. 02 - n 04 - ano 2021

Editora Acadêmica Periodicojs

$2,0 \mathrm{~g} \mathrm{~kg}^{-1}$ de fósforo $(0,2 \%)$ na limitado, o primeiro consiste em

matéria seca (NOVAIS et al., aumentar o conteúdo absorvidos 2007).

do solo, já o segundo baseia-se

As plantas, devido à na eficiência vegetal de elevar a baixa disponibilidade do $\mathrm{P}$, neprodução de biomassa utilizando cessitam de um mecanismo de o nutriente absorvido (ELLIOTT; absorção bastante eficiente, uma vez que adquirem o fósforo conLÄUCHLI, 1985).

$\mathrm{Na}$ faixa de ph que comtra um elevado gradiente de concentração da membrana plasmática, pois as concentrações de $\mathrm{P}$ inorgânico nas células vegetais (da ordem de $\mathrm{mmol} \mathrm{L}^{-1}$ ) são superiores àquelas na solução do solo (da ordem de $\mu \mathrm{mol} \mathrm{L}^{-1}$ ) (RAGOTHAMA, 2000).

O fósforo provoca a existência de sistemas radiculares maiores que aumentam a área de contato entre as raízes e o solo, devido ser um elemento pouco móvel no solo. As plantas utilizam principalmente dois mecanismos com intuito de assegurar o suprimento de $\mathrm{P}$ em ambientes onde este elemento é preende entre 4,5 e 6,0 na solução do solo, os percentuais de absorção de fósforo são maiores, predominando nestas condições a forma $\mathrm{H} 2 \mathrm{PO} 4-$, com isso trazem indícios que as raízes absorvem preferencialmente o fósforo nesta forma (SENTENAC; GRIGNON, 1985).

Para obter maior eficiência no uso do fósforo as plantas utilizam métodos que envolvem a remobilização do fósforo interno, ocorre uma maior produção por unidade de fósforo absorvido, contornam as etapas requerentes de fósforo com alterações no metabolismo de carbono e utiliza

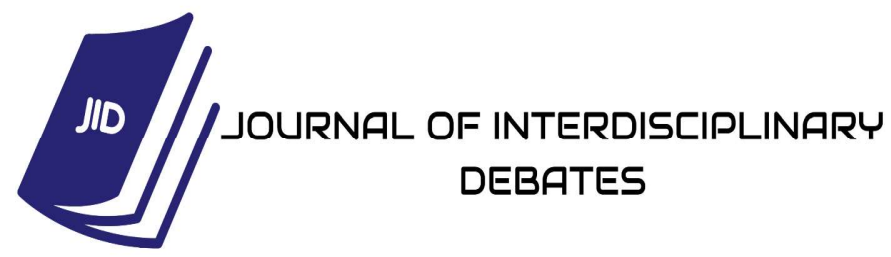


ISSN: 2675-469X

Vol. 02 - n 04 - ano 2021

Editora Acadêmica Periodicojs

de vias respiratórias alternativas (VANCE et al., 2003). É importante destacar que o P inorgânico é um nutriente altamente móvel dentro da planta, sendo mantida por meio do movimento para dentro e para fora dos vacúolos sua homeostase a nível celular e a regulação do seu influxo e efluxo (ARAÚJO; MACHADO, 2006).

Diferentemente do que ocorre com o sulfato e o nitrato no tocante a assimilação, o fosfato não sofre redução, portanto, sendo utilizado na sua forma oxidada de ortofosfato. Logo em seguida a sua absorção, o fosfato continua como P inorgânico, ou por meio de um grupo de hidroxil em uma cadeia de carbono, sofre um processo de esterificação ficando como éster simples de fosfato, ou ainda pode sofrer ligações pirofosfato de alta energia tais como o ATP, ficando preso a outro fosfato (MARSCHNER,
1995).

A forma inorgânica é a principal forma de transporte de $\mathrm{P}$ no xilema, quando absorvido pela raiz ocorre a ligeira incorporação em moléculas orgânicas (ADP, ATP, etc.). Para ser transportado via xilema para às demais parte da planta, ocorre o início do processo de hidrólise da molécula do fósforo, resultando em P inorgânico o qual é transportado via xilema em solução (LOUGHMAN, 1981).

No floema ocorre o mesmo, simultaneamente, também na forma inorgânica, registrando-se velocidades da ordem de $80 \mathrm{~cm} \mathrm{~h}^{-1}$ entre as lâminas das folhas e o floema dos pecíolos, também são detectados no floema compostos orgânicos como nucleotídeos e hexoses fosfatos. O padrão de redistribuição do fósforo ao longo da planta segue a relação fonte dreno preferen-

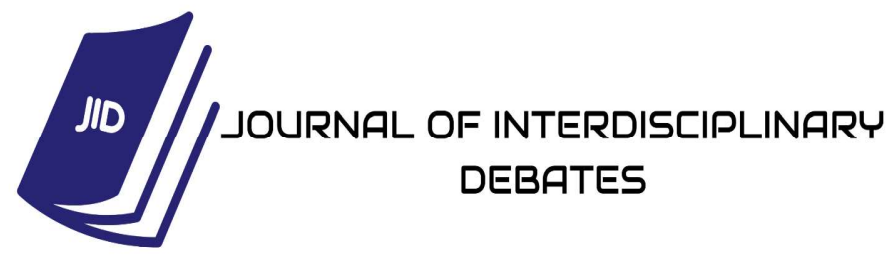


ISSN: 2675-469X

Vol. 02 - n 04 - ano 2021

Editora Acadêmica Periodicojs

cialmente, de acordo com a necessidade da planta e devido ser um nutriente altamente móvel (BIELESKI, 1973).

Aplicado por via foliar o P é rapidamente absorvido e levado para outras regiões da planta, como por exemplo, o dos tecidos vegetais em crescimento ativo. Estima-se que, no tocante ao rendimento na absorção, 50\% do fósforo que foi aplicado nas folhas seja absorvido cerca de cinco dias após a pulverização (THORNE， 1958; KANNAN, 1990). Devido até o momento não se ter nenhuma formulação de $\mathrm{P}$ que possa ser aplicada em quantidades suficientes para suprir as demandas das culturas, também não tem nenhum registro de aplicação por essa via. Sendo aplicado somente no solo (ARAÚJO; MACHADO, 2006).

Quando o P disponível não atender a demanda da plan- ta, apresentando deficiência no suprimento via radicular, a planta envia este nutriente das folhas velhas para as novas e para as raízes, este procedimento envolve reações como a quebra de fósforo orgânico e a depleção das reservas de fósforo inorgânico (SCHATMAN et al., 1998), estima-se que entre $40-47 \%$ do fosforo orgânico e 26-38\% do fósforo inorgânico reabsorvido nas folhas velhas seja oriundo da hidrolise de ácidos nucléicos e fosfolipídios(AERTS, 1996).

Quando comparado a outros nutrientes, essa translocação ocorre preferencialmente para os grãos, apresentando proporção de fósforo nos grãos superior em relação à biomassa. Esse fenômeno segundo relato de alguns autores, ocorre por causa da quantidade de carboidratos presente no grão, o que diluiria uma quantidade de fósforo controlada

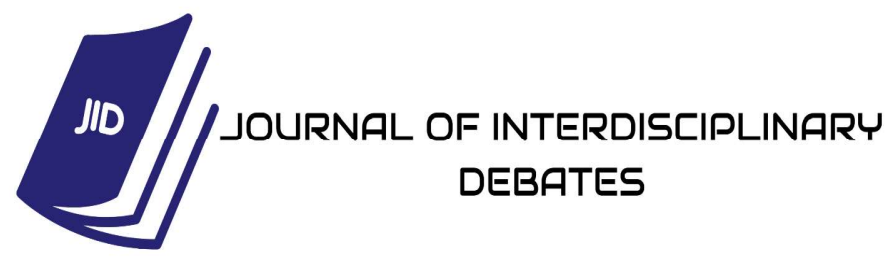


Vol. 02 - n 04 - ano 2021

Editora Acadêmica Periodicojs

por fatores genéticos (HAAG et al., 1967; FEIL et al., 1992).

Ao interagir com outros nutrientes como do caso do $\mathrm{P}$ interagindo com o nitrogênio, acorre uma sinergia, de modo que os dois nutrientes sob doses adequadas irão promover ganhos de produção maiores em relação à aplicação de cada nutriente separadamente (SHUMAN, 1994). O fósforo desempenha nas reações fotossintéticas e no metabolismo de $\mathrm{C}$ um relevante papel, esses processos são fundamentais para a assimilação e uso de N (ARAÚJO; MACHADO, 2006).

Atuação de agentes biológicos para a fixação de fósforo nas plantas

As bactérias e fungos do solo predominantemente dos gêneros Bacilus, Pseudomonas, Penicillium e Aspergilus são mi- crorganismos solubilizadores de fosfatos. Em solos rizosférico estão presentes cerca de $40 \%$ destes microrganismos (RICHARDSON,2001).

Por promover o crescimento e proporcionar o aumento da disponibilidade de nutrientes para os vegetais com a combinação de um ou mais dos seguintes mecanismos: maior desenvolvimento de raiz favorecendo a absorção de água, controle biológico de patógenos, produção de hormonas, fixação de nitrogênio, mineralização do fósforo orgânico e solubilização de fósforo inorgânico e outros nutrientes. Tem crescido o interesse na manipulação das riziobactérias promotoras do crescimento (RPCPs), principalmente as do gênero Pseudomonas, com o intuito de aumentar a eficiência da utilização de fertilizantes nos sistemas agrícolas (OLIVEIRA et al. 2003;

\section{NID}


ISSN: $2675-469 X$

Vol. 02 - n 04 - ano 2021

Editora Acadêmica Periodicojs

RODRÍGUEZ e FRAGA,1999; cam-se: o algodão, o amendoim,

ZAIDI e MOHAMMAD, 2006)

Por sua vez, os fungos micorrízicos surgiram na mesma época que coincide com o aparecimento das plantas terrestres, ou seja, há 400 milhões de anos (BERBARA et al., 2006). Dentre os sete tipos distintos de associações micorrízicas apenas as ectomicorrizas e as micorrizas arbusculares são mais importantes e frequentes (MOREIRA e SIQUEIRA,2002). Em torno de 70 a $90 \%$ dos vegetais fazem associação com os fungos micorrízico arbusculares (FMAs) sendo muito comum na natureza, indica que entre a raiz e o fungo existe uma simbiose mutualística (MOREIRA e SIQUEIRA, 2006; PARNISKE,2008).

Dentre algumas espécies de vegetais de importância econômica que servem como hospedeiras dos FMAs desta- a mamona e o gergelim. Criadas

pelo processo da simbiose, as hifas atuam exercendo a função extensora das raízes e transferem por meio dos arbúsculos, que são estruturas intercelulares efêmeras, nutrientes minerais e água para as plantas. Por sua vez, a planta transfere fotoassimilados para os fungos (RAVEN et al., 1996).

Através da simbiose os fungos podem fornecer um benefício nutricional de cerca de $10 \%$ de potássio, 25\% de nitrogênio, $80 \%$ do fósforo, $25 \%$ do zinco e $60 \%$ do cobre para o seu hospedeiro (MARSCHNER e DELL, 1994).

\section{MATERIAL E MÉTODOS}

\section{Área experimental}

O experimento foi con-

\section{NID}


Vol. 02 - n 04 - ano 2021

Editora Acadêmica Periodicojs

duzido no período de 31 outubro de 2017 a 6 março de 2018 no Sítio Madeira Cortada, situado na zona rural de Missão Velha-CE, com $360 \mathrm{~m}$ de altitude, com latitude sul de $7^{\circ} 13^{\prime} 41^{\prime \prime}$ e longitude oeste de $39^{\circ} 10^{\prime} 43^{\prime \prime}$. Na Figura 1 é mostrado a área total da propriedade e a localização em que o experimento foi conduzido.

Figura 1. Vista aérea do Sítio Madeira Cortada, destacando-se a área total da propriedade em vermelho e o local do experimento delimitado pelo quadrado amarelo.

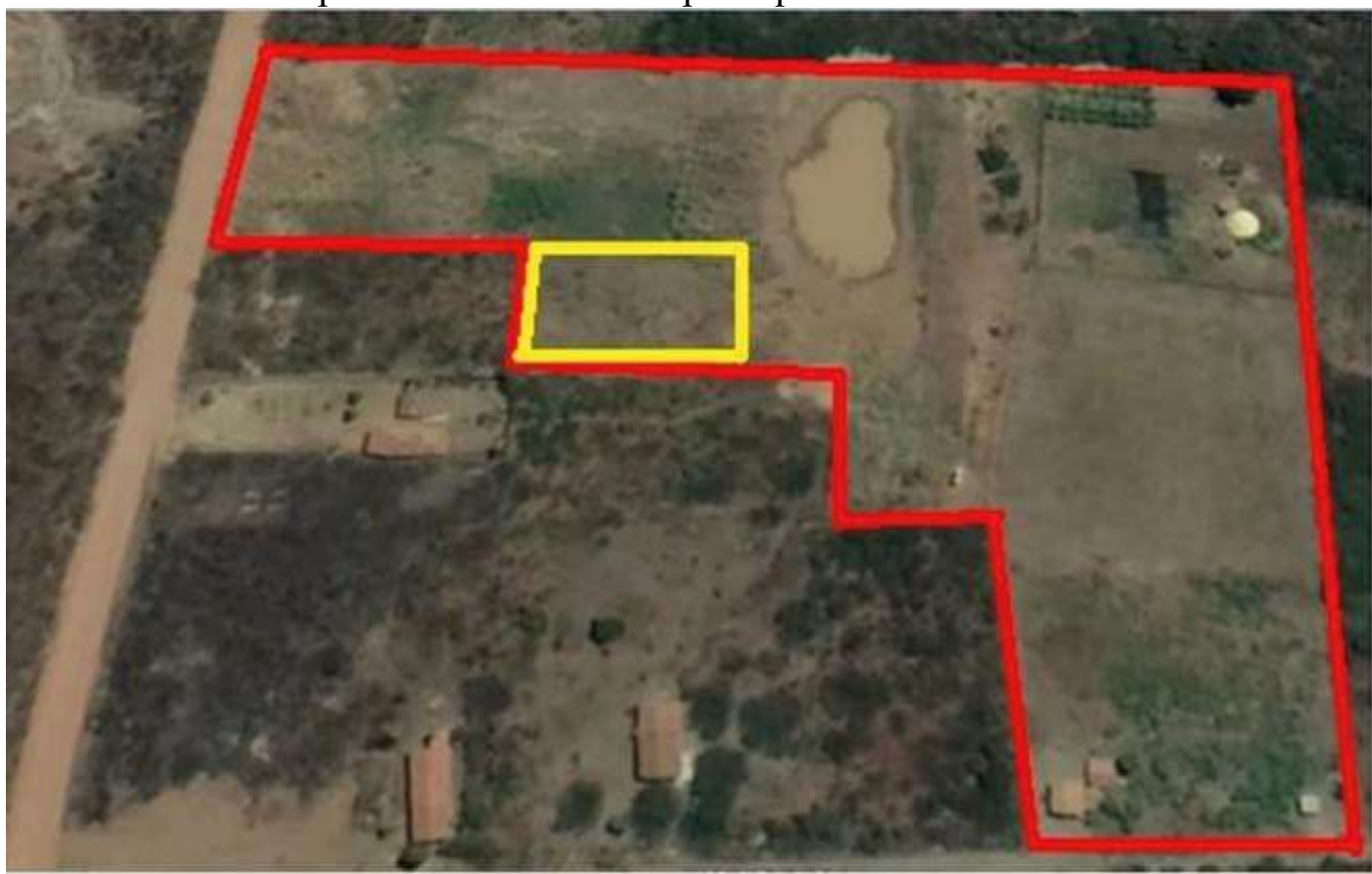

Fonte: Google Maps (2018).

\section{Clima e solo}

De acordo com a classificação de Köppen, o clima onde está localizada a área experimental é Aw’ (ALVARES et al., 2013). Considerado clima tropical, com inverno característico seco, com estação chuvosa predominante entre o final de novembro a abril e estação seca no inverno entre os meses de maio a outubro. As precipitações nas regiões de clima Aw' geralmente são superio-

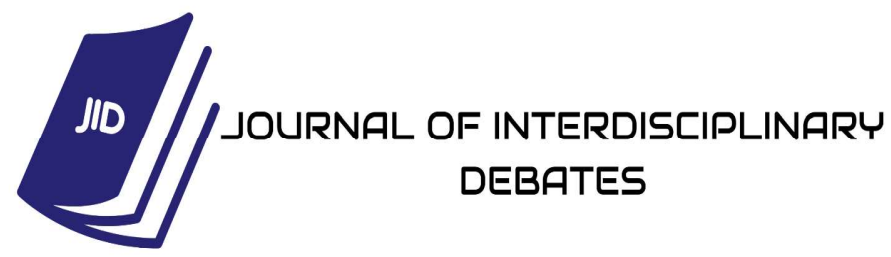


ISSN: $2675-469 \mathrm{X}$

Vol. 02 - n 04 - ano 2021

Editora Acadêmica Periodicojs

res a $750 \mathrm{~mm}$ anuais, sendo 942

$\mathrm{mm}$ anuais no município de Missão Velha-CE.

De acordo com o sistema brasileiro de classificação de solos e tendo por base o mapa de reconhecimento de média intensidade de solo realizado pela Funceme (2012), o solo da área experimental é classificado como Latossolo Vermelho Amarelo típico. O mesmo também apresenta relevo plano e textura da camada superficial do solo classificada como arenosa.

$\mathrm{Na}$ área experimental foi realizada a análise química do solo coletando-se amostras de 0-20 $\mathrm{cm}$ de profundidade, sendo o método utilizado para determinação da constituição do solo o Mehlich $^{-1}$. O solo possuía $\mathrm{pH}$ (1:2,5 H2O): 7,0; P: 4,35 mg dm 3; $\mathrm{K}: 1,9 \mathrm{mmolc} \mathrm{dm}^{-3}$; $\mathrm{Ca}: 22,4$ mmolc $\mathrm{dm}^{-3}$; Mg: 12,2 mmolc $\mathrm{dm}^{-3} ; \mathrm{H}+\mathrm{Al}:$ 4,6 mmolc dm $\mathrm{dm}^{-3}$, Ma- téria orgânica: $3,50 \mathrm{~g} \mathrm{~kg}^{-1}$, CTC:

42,4 mmolc dm ${ }^{-3}$ e V (\%): 89,09.

\section{Delineamento experimental}

O experimento foi realizado em delineamento em blocos casualizados em esquema de parcela subdividida, com três repetições. As parcelas foram compostas por quatro doses de fósforo $(0,25,50$ e $100 \%$ da dose recomendada) e as subparcelas ao uso do inoculante PhosphoBarvar-2 (com e sem), totalizando assim 24 observações, conforme a designação dos tratamentos e o croqui (Tabela 2 e Figura 2). Contendo bactérias dos gêneros Pseudômonas e Pantoea Agglomerans o PhoshoBarvar-2 tem a função de proporcionar efeitos positivos sobre o desenvolvimento das plantas influenciando na germinação, na emergência e no crescimento (COSTA et al.,2013).

\section{IID}


ISSN: 2675-469X

Vol. 02 - n 04 - ano 2021

Editora Acadêmica Periodicojs

Tabela 2 - Combinação dos fatores em cada tratamento e suas respectivas designações

\begin{tabular}{|c|c|c|c|}
\hline $\begin{array}{l}\text { Parcela } \\
\text { Doses }(\mathrm{P})\end{array}$ & $\begin{array}{r}\text { Subparcela } \\
\text { Bavar (B) }\end{array}$ & Tratamento & Designação dos tratamentos \\
\hline \multirow{2}{*}{$\mathrm{n} n$} & $\mathrm{Bc}$ & $\mathrm{D} 0 \mathrm{Bc}$ & 0\% Fósforo com PhosphoBarvar-2 \\
\hline & Bs & D0Bs & 0\% Fósforo sem PhosphoBarvar-2 \\
\hline \multirow[t]{2}{*}{$\mathrm{D} 25$} & DU & $\mathrm{D} 25 \mathrm{Bc}$ & 25\% Fósforo com PhosphoBarvar-2 \\
\hline & Bs & $\mathrm{D} 25 \mathrm{Bs}$ & $25 \%$ Fósforo sem PhosphoBarvar-2 \\
\hline \multirow[t]{2}{*}{ D50 } & & D50Bc & 50\% Fósforo com PhosphoBarvar-2 \\
\hline & Bs & D50Bs & $50 \%$ Fósforo sem PhosphoBarvar-2 \\
\hline \multirow[t]{2}{*}{ D100 } & & D100Bc & $100 \%$ Fósforo com PhosphoBarvar-2 \\
\hline & Bs & D100Bs & $100 \%$ Fósforo sem PhosphoBarvar-2 \\
\hline
\end{tabular}

Figura 2 - Croqui da área experimental

\begin{tabular}{|c|c|c|c|c|c|}
\hline \multicolumn{2}{|c|}{ Bloco } & \multicolumn{2}{c|}{ Bloco 2 } & \multicolumn{2}{c|}{ Bloco 3 } \\
\hline $\mathrm{D} 0 \mathrm{Bc}$ & $\mathrm{D} 0 \mathrm{Bs}$ & $\mathrm{D} 50 \mathrm{Bs}$ & $\mathrm{D} 50 \mathrm{Bc}$ & $\mathrm{D} 0 \mathrm{Bc}$ & $\mathrm{D} 0 \mathrm{Bs}$ \\
\hline $\mathrm{D} 100 \mathrm{Bc}$ & $\mathrm{D} 100 \mathrm{Bs}$ & $\mathrm{D} 25 \mathrm{Bs}$ & $\mathrm{D} 25 \mathrm{Bc}$ & $\mathrm{D} 100 \mathrm{Bc}$ & $\mathrm{D} 100 \mathrm{Bs}$ \\
\hline $\mathrm{D} 25 \mathrm{Bs}$ & $\mathrm{D} 25 \mathrm{Bc}$ & $\mathrm{D} 100 \mathrm{Bs}$ & $\mathrm{D} 100 \mathrm{Bc}$ & $\mathrm{D} 50 \mathrm{Bs}$ & $\mathrm{D} 50 \mathrm{Bc}$ \\
\hline $\mathrm{D} 50 \mathrm{Bs}$ & $\mathrm{D} 50 \mathrm{Bc}$ & $\mathrm{D} 0 \mathrm{Bs}$ & $\mathrm{D} 0 \mathrm{Bc}$ & $\mathrm{D} 25 \mathrm{Bc}$ & $\mathrm{D} 25 \mathrm{Bs}$ \\
\hline
\end{tabular}

Cada parcela experimental totalizava $9 \mathrm{~m}^{2}$, sendo três metros de largura por três metros de comprimento. A parcela útil, utilizada para análise, foi composta pelas fileiras centrais da cultura, com um metro de comprimento, e retirando cinco plantas de cada parcela, eliminando-se as extremidades (bordadura) e consequentemente reduzindo o efeito das parcelas localizadas ao redor.
Para interpreta e comparar os resultados, os dados foram submetidos à análise de variância (ANOVA) pelo teste $\mathrm{F}$ e as médias do fator PhosphoBarvar-2 comparadas pelo teste de Tukey a $5 \%$ de probabilidade e o fator dose de fósforo foi submetido à análise de regressão para seleção do modelo com maior expoente significativo. Utilizou-se o programa estatístico Sisvar 5.3 para as análises estatísticas.

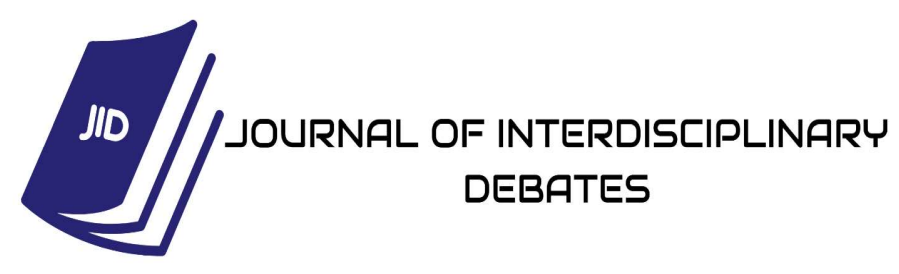


ISSN: 2675-469X

Vol. 02 - n 04 - ano 2021

Editora Acadêmica Periodicojs

com $0,1 \mathrm{~m}$ de profundidade (Fi-

\section{Condução do experimento}

$\mathrm{O}$ experimento foi implantado no final de outubro de 2017 com a gradagem da área para preparo do solo. No dia 31 de outubro de 2017, para a realização da semeadura foram abertos sulcos espaçados a $0,9 \mathrm{~m}$, gura 3), utilizando-se enxadas.

Aplicou-se a adubação de acordo com cada tratamento no fundo do sulco, e em seguida cobriu-se com uma camada de solo de aproximadamente $0,05 \mathrm{~m}$.

Figura 3. Visão dos sulcos abertos para a realização da adubação de fundação e posterior semeadura do gergelim.

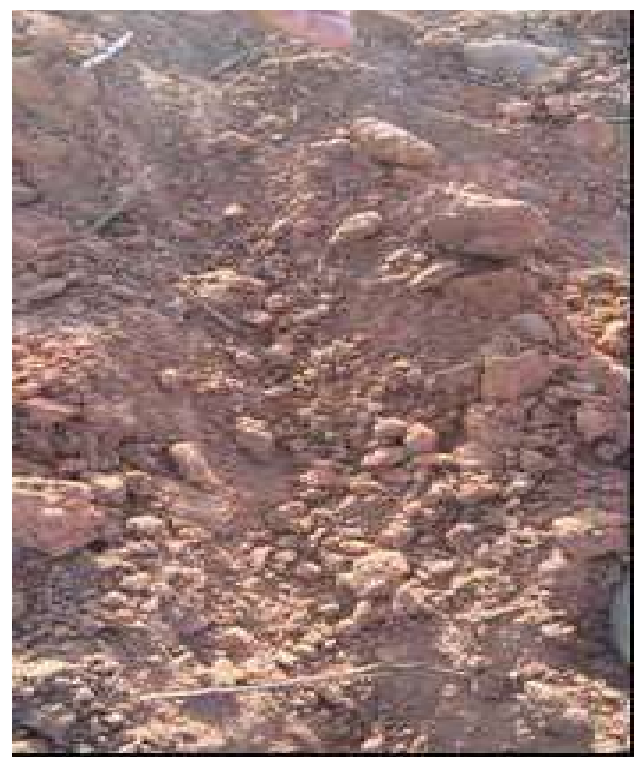

Fonte: Acervo pessoal (2017).

A dose utilizada na se- ções da EMBRAPA (2008), com meadura referente ao tratamena dose de $10 \mathrm{~kg} \mathrm{ha}^{-1}$ de nitrogênio to $100 \%$ foi obtida com base na (100 kg ha-1 de sulfato de amôanálise de solo e as recomendanio), $80 \mathrm{~kg} \mathrm{ha}^{-1}$ de P2O5 (444 kg

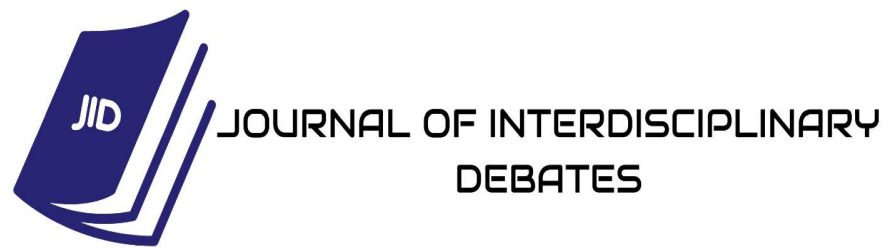


ISSN: 2675-469X

Vol. 02 - n 04 - ano 2021

Editora Acadêmica Periodicojs

ha $^{-1}$ de superfosfato simples) e 20 $\mathrm{kg} \mathrm{ha}^{-1}\left(33,33 \mathrm{~kg} \mathrm{ha}^{-1}\right.$ de cloreto de potássio). As demais doses utilizadas foram variações proporcionais destas.

Para os tratamentos com inoculação das sementes com PhosphoBarvar-2, antes da semeadura foi realizada a inoculação das sementes, utilizando-se a dose de $100 \mathrm{~g}$ do produto comer- cial por hectare, diluído em 10

L de água (Figura 4). O produto

também foi aplicado diretamente

no solo sobre as sementes na dose de $100 \mathrm{~g}$ do produto comercial por hectare, diluído em 200 L de água (Figura 5). A semeadura foi realizada em fluxo contínuo devido ao tamanho das sementes (Figura 6).

Figura 4. Inoculação das sementes do gergelim com o PhosphoBarvar-2.

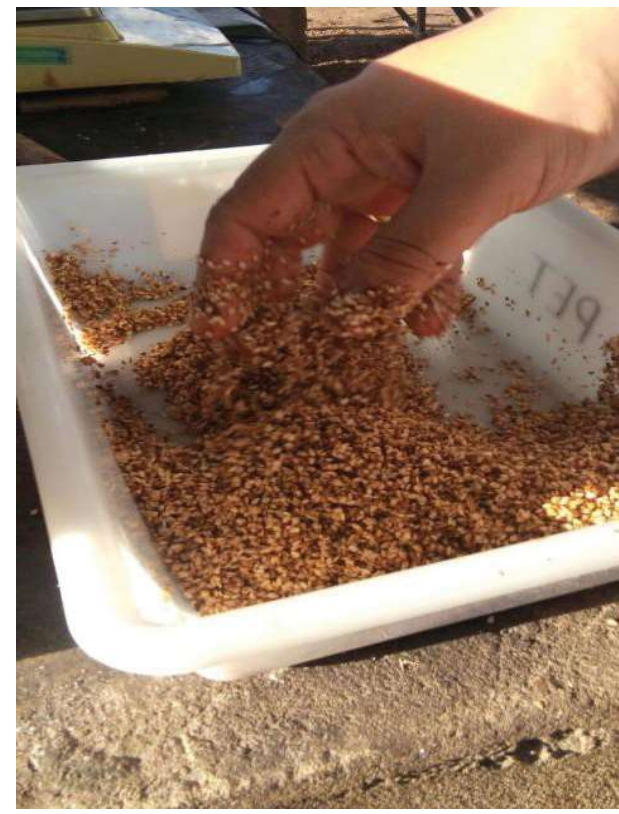

Fonte: Acervo pessoal (2017).

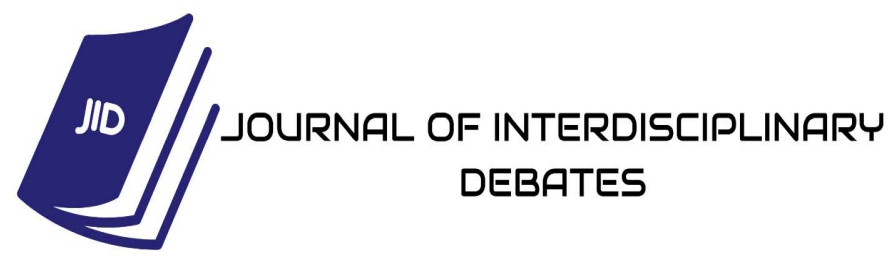


ISSN: $2675-469 \mathrm{X}$

Vol. 02 - n 04 - ano 2021

Editora Acadêmica Periodicojs

Figura 5. Aplicação do PhosphoBarvar-2 diretamente no solo.

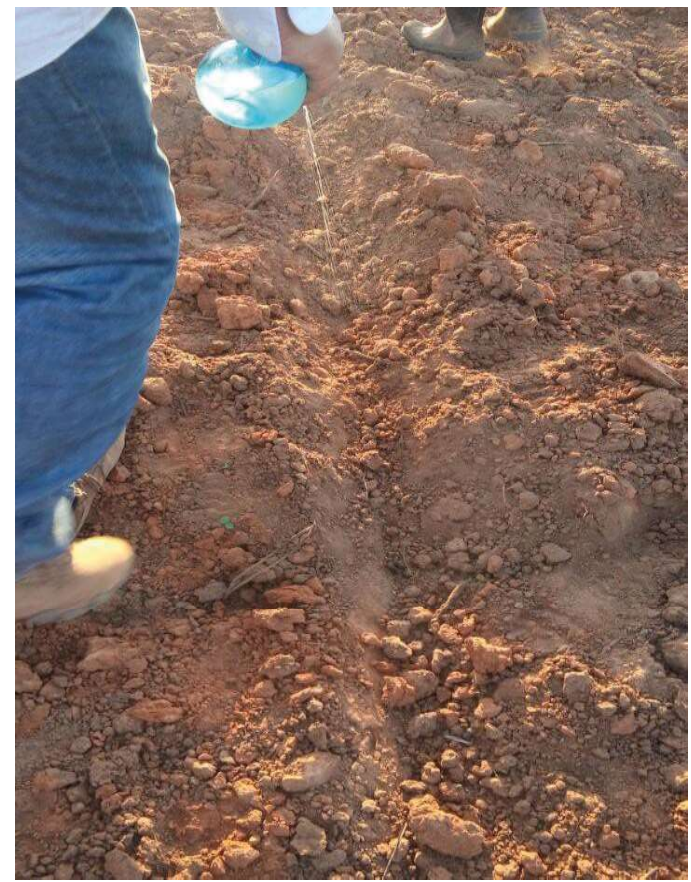

Fonte: Acervo pessoal (2017)

Figura 6. Semeadura manual do gergelim.

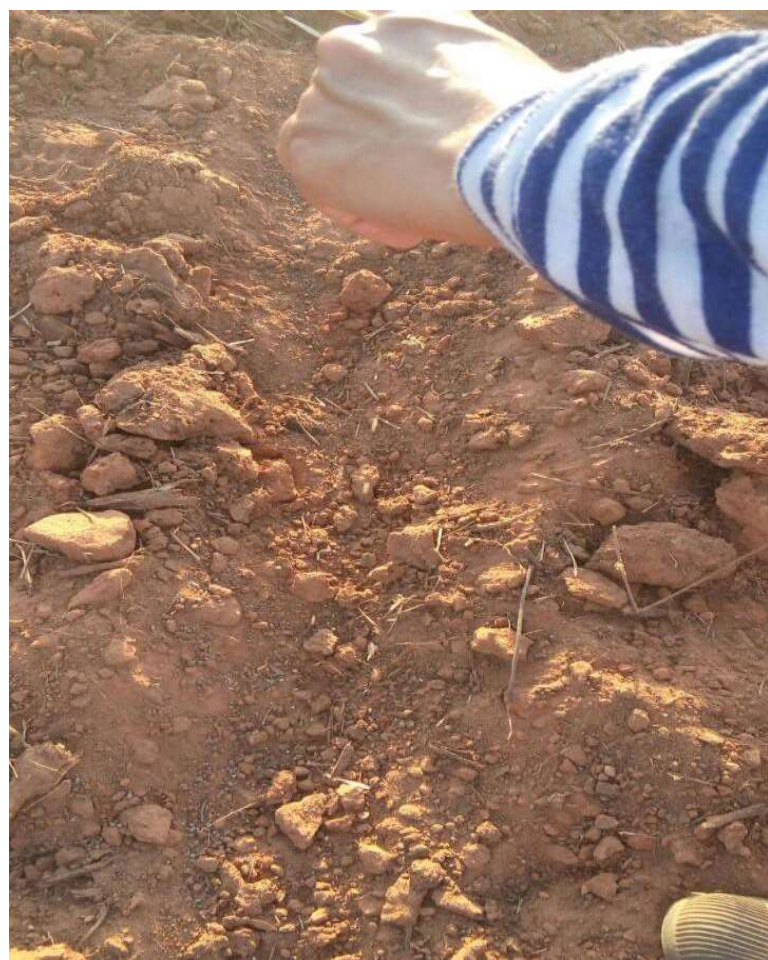

Fonte: Acervo pessoal (2017).

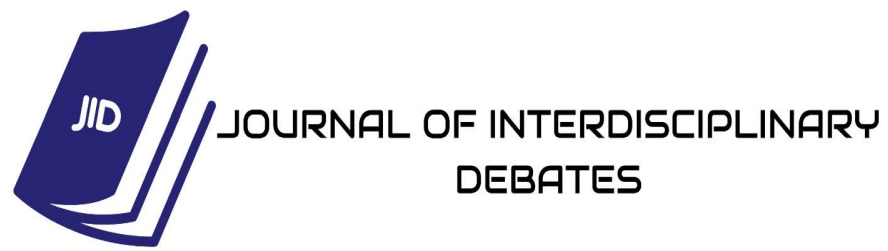


ISSN: 2675-469X

Vol. 02 - n 04 - ano 2021

Editora Acadêmica Periodicojs

No dia 07 de novembro de 2017 foi identificado as primeiras emergências das plântulas do gergelim (Figura 7). No dia 15 de novembro foi realizado o primeiro desbaste das plantas deixando uma planta a cada $0,20 \mathrm{~m}$ (Figura 8). A prática foi repetida no dia 29 do mesmo mês e junto à mesma foi realizada a adubação de cobertura nitrogenada (Figura 9), com a dose $100 \%$ sendo de
$50 \mathrm{~kg} \mathrm{ha}^{-1}$ de nitrogênio $(250 \mathrm{~kg}$ ha' ${ }^{-1}$ de sulfato de amônio). Realizou-se também outra aplicação de PhosphoBarvar-2 diretamente na planta, a aplicação do produto foi feita apenas nas parcelas com uso do produto, sendo aplicados a dosagem de $100 \mathrm{~g}$ do produto comercial, diluídos em 200 L de água (Figura 10).

Figura 7. Emergência das plântulas do gergelim.

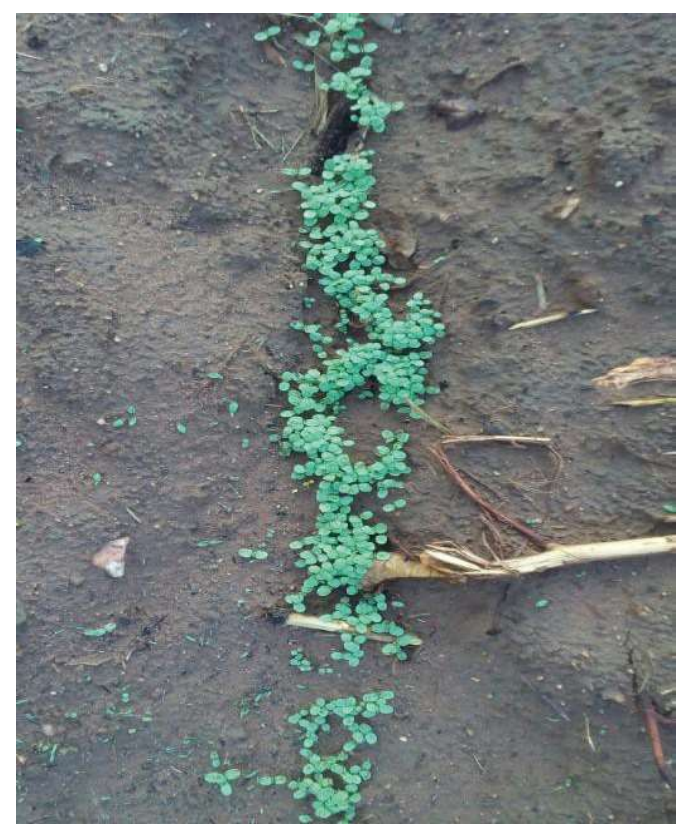

Fonte: Acervo pessoal (2017)

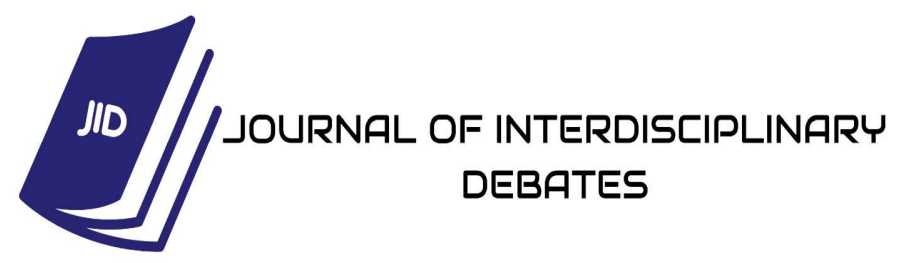


ISSN: 2675-469X

Vol. 02 - n 04 - ano 2021

Editora Acadêmica Periodicojs

Figura 8. Espaçamento das plantas após o desbaste.

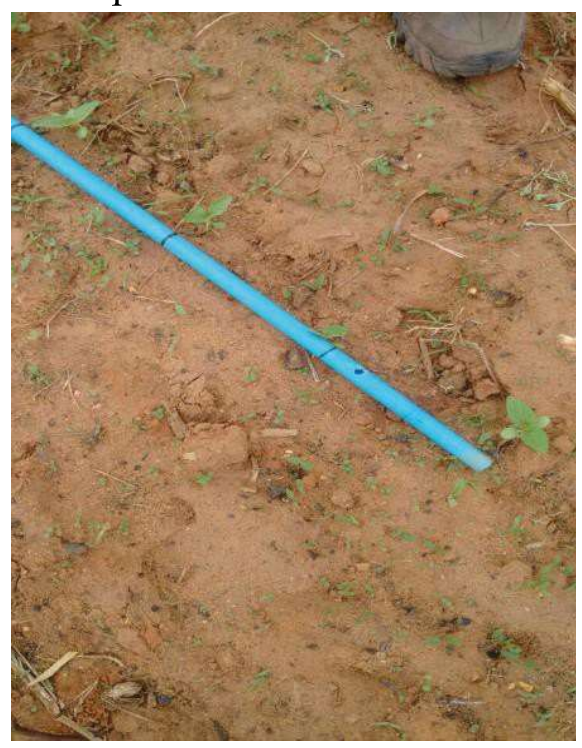

Fonte: Acervo pessoal (2017)

Figura 9. Aplicação da adubação de cobertura.

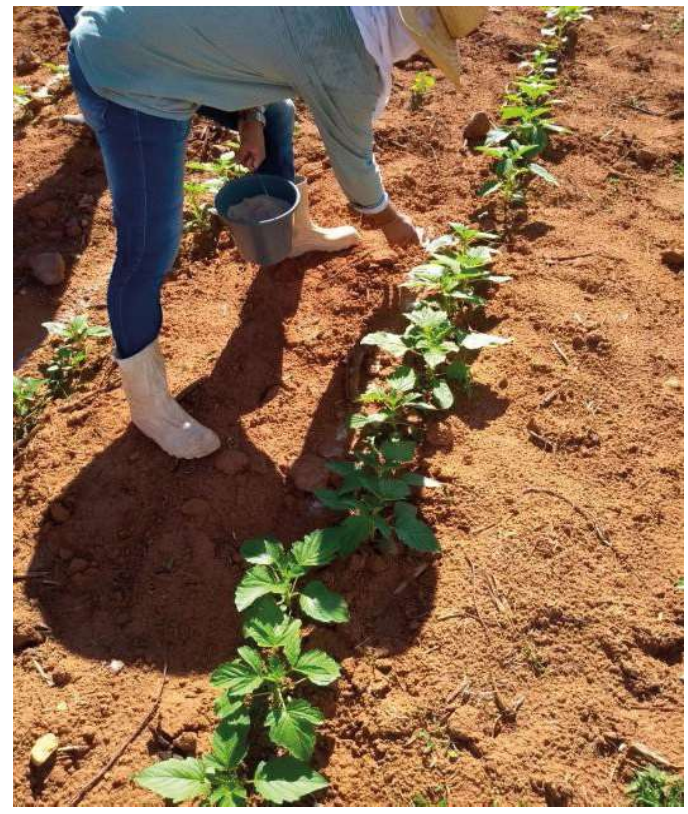

Fonte: Acervo pessoal (2017)

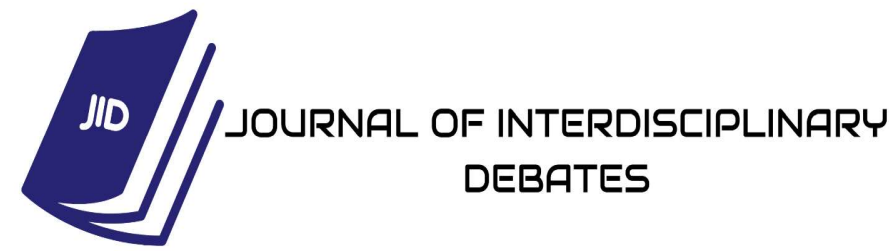


Figura 10. Aplicação do PhosphoBarvar-2 diretamente na planta.

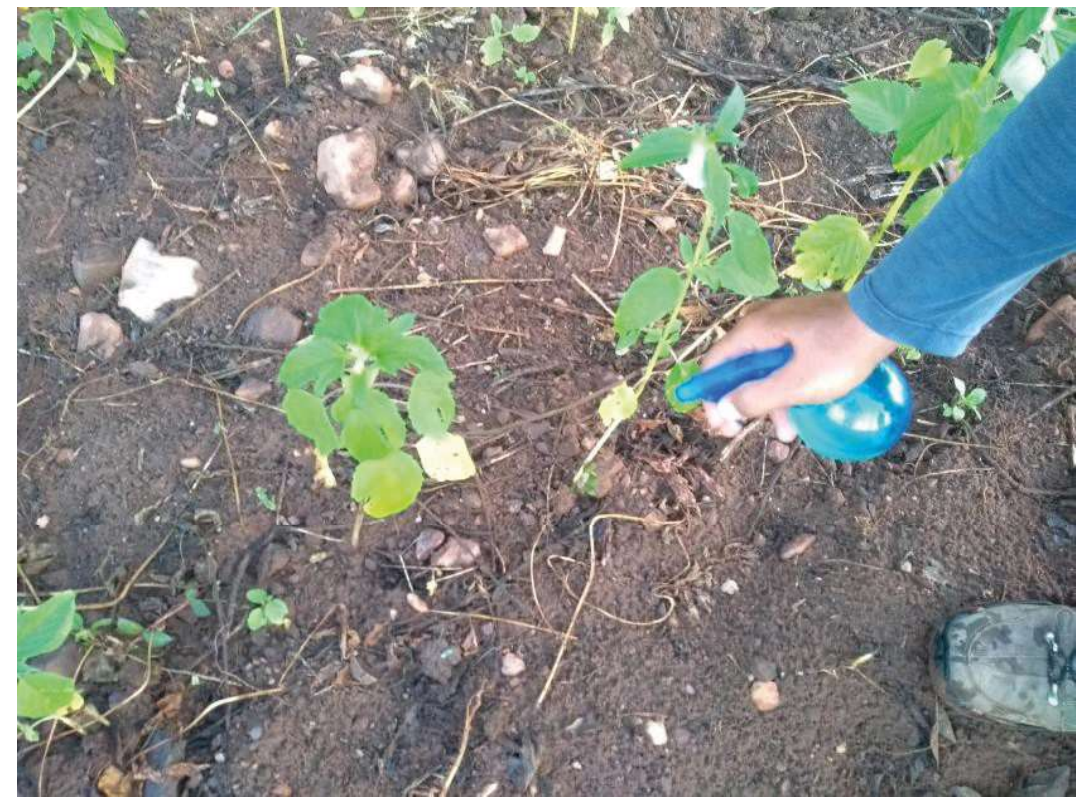

Fonte: Acervo pessoal (2017)

Durante o experimento fita métrica tendo por base o níforam realizados capinas manual vel do solo até o ápice do ramo com enxadas no intuito de con- principal (Figura 11). Para o ditrolar as plantas invasoras. âmetro do colmo (Figura 12) o instrumento utilizado foi um paAvaliação das características químetro tendo como base uma agronômicas altura de aproximadamente 0,10 m do nível do solo. Os dados de

Altura da planta, diâmetro do colmo e comprimento das vagens

A altura da planta foi medida com o auxílio de uma altura das plantas e diâmetro das plantas foram obtidos através da medida de cinco plantas retirada de cada parcela amostral e em seguida foi feito uma média dos dados obtidos.

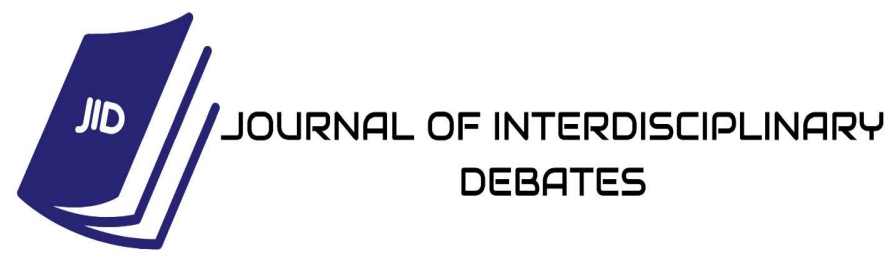


ISSN: $2675-469 X$

Vol. 02 - n 04 - ano 2021

Editora Acadêmica Periodicojs

O paquímetro também média feita do número de dez va-

foi utilizado no comprimento das gens de cada parcela amostral.

vagens (Figura 13), esses valores

foram obtidos através de uma

Figura 11. Medição da altura das plantas.

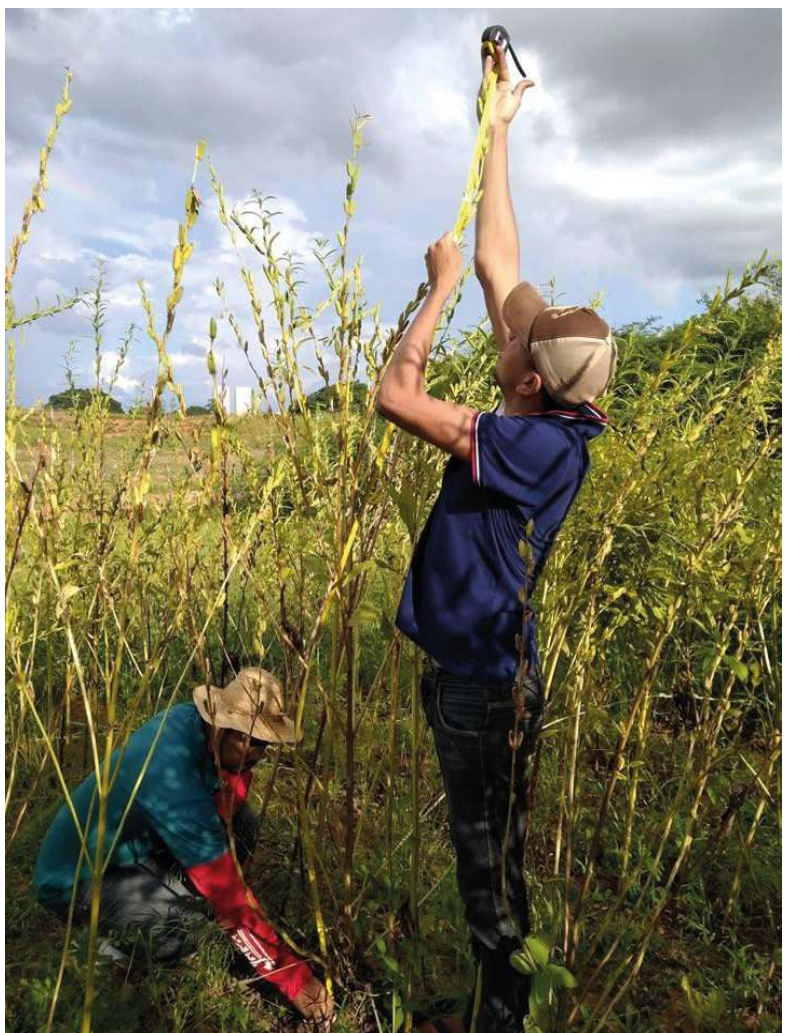

Fonte: Acervo pessoal (2018).

Figura 12. Medição do diâmetro do colmo das plantas da parcela útil com paquímetro.

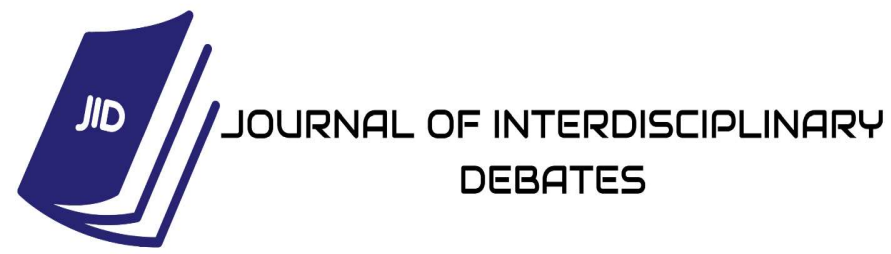


Vol. 02 - n 04 - ano 2021

Editora Acadêmica Periodicojs

Figura 12. Medição do diâmetro do colmo das plantas da parcela útil com paquímetro.

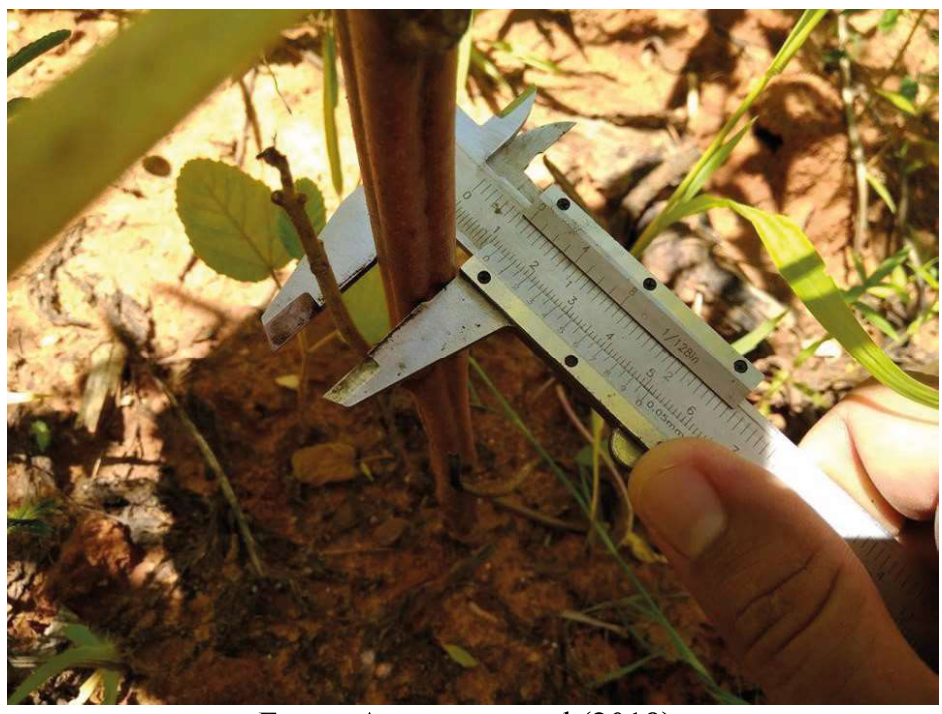

Fonte: Acervo pessoal (2018).

Figura 13. Medição do comprimento de dez vagens de cada parcela amostral com paquímetro.

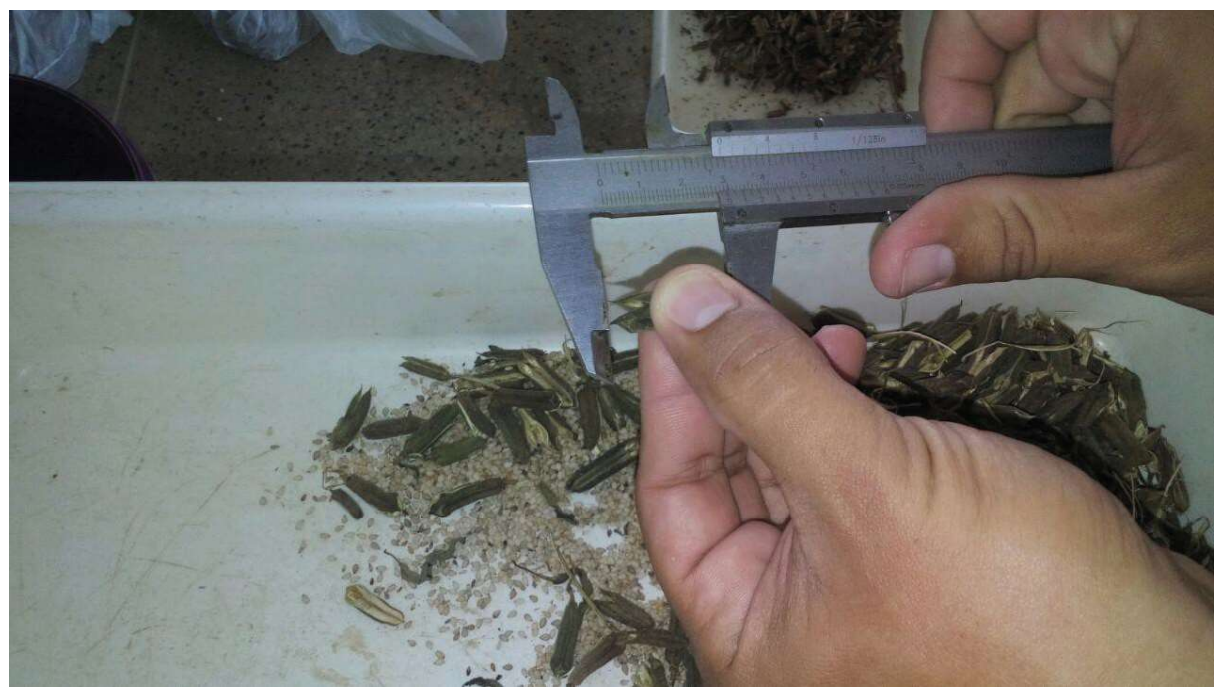

Fonte: Acervo pessoal (2018).

Número de vagens, peso total, obtido através da retirada e con-

massa das vagens e massa de 50

sementes

O número de vagens foi tagem manual de todas as vagens das cinco plantas retiradas de cada parcela amostral, em seguida as mesmas foram pesadas em

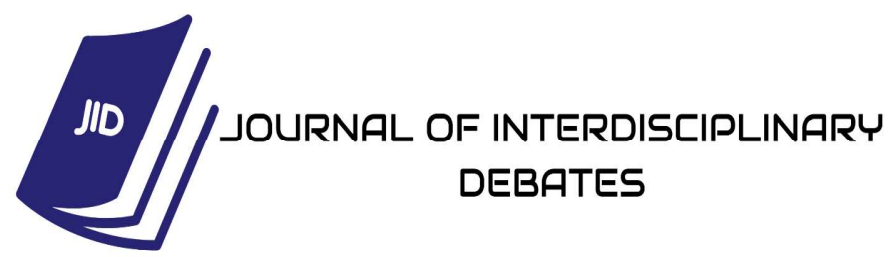


ISSN: $2675-469 X$

Vol. 02 - n 04 - ano 2021

Editora Acadêmica Periodicojs

uma balança semianalítica para se obter o peso total das vagens (Figura 14).

Após a contagem das vagens, fez-se a separação das sementes e em seguida foram pesadas para se obter a massa das vagens e a massa de 50 sementes de cada parcela amostral avalia- da (Figura 15). Para análise dos dados as sementes foram estimadas no número de 1000 sementes para cada parcela.

Para se obter os dados descritos as vagens de cada parcela foram colocadas antes para serem secadas a luz natural.

Figura 14. Aferição do peso total das vagens.

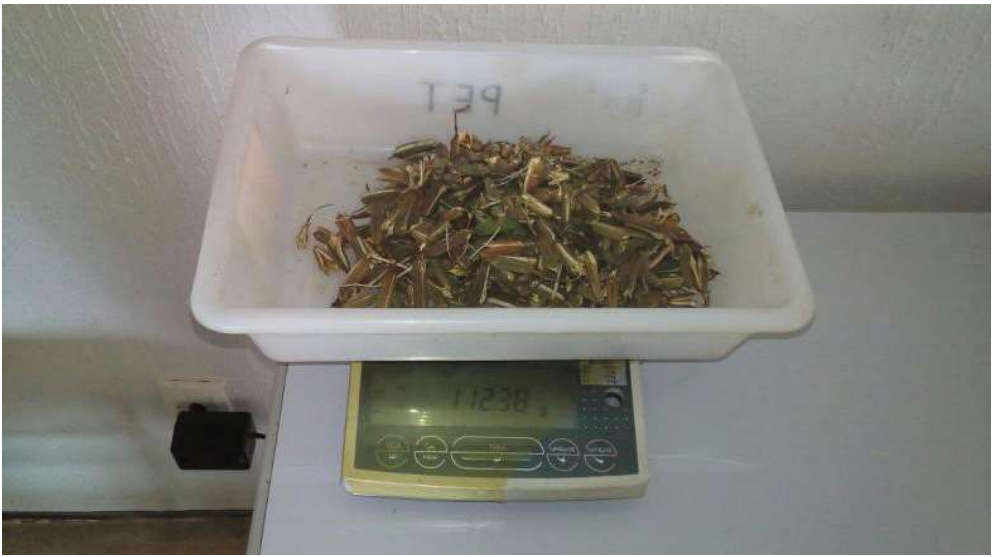

Fonte: Acervo pessoal (2018). 
Figura 15. Aferição da massa de 50 sementes retirada de cada parcela amostral.

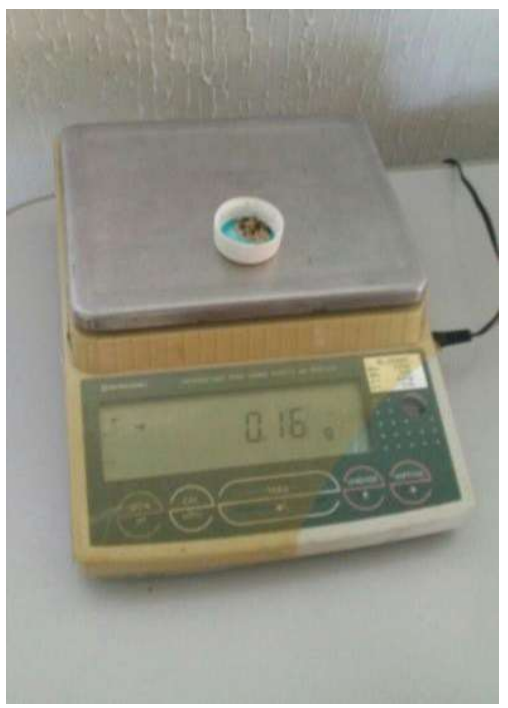

Fonte: Acervo pessoal (2018)

RESULTADOS E DISCUS- bação e para o Phosphobarvar-2 SÃO valores baixos para os coeficientes de variação, Santos (2016)

Em trabalhos de campo também obteve valores baixos sobre estatística experimental, para altura das plantas, porém, através dos seus resultados, Pi- médios para o diâmetro do colmentel Gomes (2009) elaborou mo. Perim et al. (2010) e Silva et uma classificação para o Coe- al. (2016) obtiveram valores méficiente de Variação sendo de dios para a altura.

0-10\% CVs baixos, de 10-20\%

CVs médios e de 20-30\% são considerados altos.

Com base nessa classificação as variáveis analisadas na tabela 3 apresentam para a Adu- 
ISSN: 2675-469X

Vol. 02 - n 04 - ano 2021

Editora Acadêmica Periodicojs

TABELA 3. Síntese da análise de variância para a altura das plantas (Altura), o comprimento da vagem e o diâmetro do colmo, e do teste de médias para o fator PhosphoBarvar-2

\begin{tabular}{ccccc}
\hline & & \multicolumn{3}{c}{ Valores de F } \\
\cline { 3 - 5 } Fontes de Variação & G.L. & Altura & Diâmetro colmo & $\begin{array}{c}\text { Comprimento } \\
\text { Vagem }\end{array}$ \\
\hline Bloco & 2 & $0,79^{\mathrm{NS}}$ & $0,92^{\mathrm{NS}}$ & $1,32^{\mathrm{NS}}$ \\
Adubação (A) & 3 & $1,18^{\mathrm{NS}}$ & $3,77^{*}$ & $7,64 *$ \\
Resíduo 1 & 6 & - & - & - \\
PhosphoBarvar (P) & 1 & $9,63^{*}$ & $7,28^{*}$ & $9,75^{*}$ \\
Interação A*P & 3 & $0,63^{\mathrm{NS}}$ & $1,83^{\mathrm{NS}}$ & $2,34^{\mathrm{NS}}$ \\
Resíduo 2 & 8 & - & - & - \\
\hline CV 1 (\%) & - & 7,76 & 6,28 & 3,31 \\
CV 2 (\%) & - & 5,74 & 7,43 & 4,37 \\
Média Geral & - & $2,50 \mathrm{~m}$ & $1,59 \mathrm{~cm}$ & $3,02 \mathrm{~cm}$ \\
\hline
\end{tabular}

Teste de Médias de Tukey $(\mathrm{p}<0,05)$

\begin{tabular}{ccccc}
\cline { 3 - 4 } Fatores & - & Altura & Diâmetro colmo & $\begin{array}{c}\text { Comprimento } \\
\text { Vagem }\end{array}$ \\
\cline { 3 - 5 } & & $\mathrm{M}$ & $\mathrm{cm}$ & \\
\hline PhosphoBarvar $(\mathrm{P})$ & - & $2,59 \mathrm{a}$ & $1,65 \mathrm{a}$ & $3,11 \mathrm{a}$ \\
Com & - & $2,41 \mathrm{~b}$ & $1,52 \mathrm{~b}$ & $2,94 \mathrm{~b}$ \\
Sem & - & &
\end{tabular}

Médias seguidas pela mesma letra minúscula na coluna, não diferem entre si pelo teste de Tukey a 5\% de probabilidade.

**: significativo $(\mathrm{P}<0,01)$; *: significativo $(\mathrm{P}<0,05)$; NS: não significativo; $C V \%$ : coeficiente de variação.

Na tabela 3, de acordo com a análise de variância dos dados encontrados nesse traba1ho, a interação entre as doses de adubação e o inoculante PhosphoBavar-2 não apresentou significância para as variáveis altura das plantas, diâmetro do colmo e comprimento da vagem. Na análise individual, a adubação foi significativa a $5 \%$ de probabilidade para o diâmetro do colmo e comprimento da vagem, e não significativo para a altura das plantas.

Diferente dos dados 
ISSN: 2675-469X

Vol. 02 - n 04 - ano 2021

Editora Acadêmica Periodicojs

para a altura da planta onde nesse experimento não se obteve resposta significativa, Carneiro et al. (2016) obteve resposta linear significativa a 5\% para a variável altura da planta com a aplicação de adubação fosfatada, as plantas apresentaram um aumento de 17 cm em relação as plantas testemunha.

Trabalho realizado por Bezerra et al. (2010) também não apresentou diferença significativa para altura das plantas do gergelim em função de diferentes doses de adubação. Por outro lado, Santos (2016) encontrou efeito significativo $(\mathrm{p}<0,05 \%)$ avaliando o genótipo do gergelim "BRS Seda" sobre diferentes níveis de adubação organomineral para a variável altura da planta.

Resultados positivos para a altura da planta também foram encontrados por Perim et al. (2010) com a utilização de adubação em solos de baixa fertilidade, no mesmo trabalho avaliando resposta da adubação em solo de alta fertilidade as respostas para altura da planta só foram evidenciadas nos primeiros 43 dias de crescimento.

Mesmo não obtendo efeitos significativos para a adubação na variável altura, e levando-se em conta o valor médio $(2,5$ m), o experimento obteve uma melhor resposta em relação aos trabalhos realizados por Alves (2014), Maia Filho et al. (2010), Lima (2006), Pereira et al. (2002) que obtiveram aturas de $1,3 \mathrm{~m}$, $1,56 \mathrm{~m}, 0,96 \mathrm{~m}$ e $1,26 \mathrm{~m}$, respectivamente, ao estudarem diversos fatores de crescimento e desenvolvimento utilizando adubação orgânica de origem bovina.

Para as variáveis diâmetro do colmo e comprimento da vagem (Tabela 3, Gráfico 1), verifica-se que ocorreu diferen-

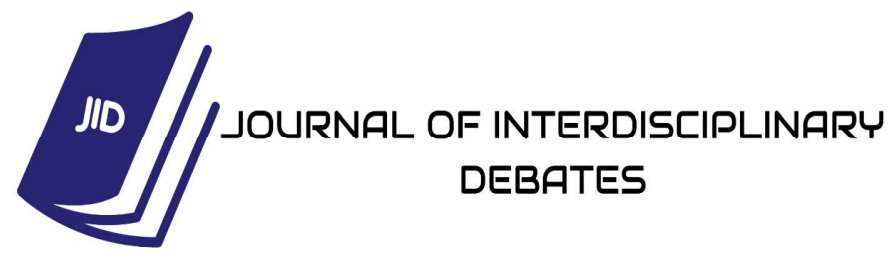


ISSN: 2675-469X

Vol. 02 - n 04 - ano 2021

Editora Acadêmica Periodicojs

ça significativa, com modelo de regressão polinomial de segunda ordem significativo $(\mathrm{p}<0,05)$, com maiores valores observados nas doses de $55 \%$ e $32 \%$ da dose recomendada de fósforo, estabelecendo resultados de $1,66 \mathrm{~cm} \mathrm{e}$ 3,09 cm para diâmetro do colmo e comprimento da vagem, respectivamente.

O gergelim necessita desenvolver bem o seu caule para evitar o tombamento e dar uma melhor sustentação à produção de ramos, folhas e frutos. Sendo um critério importante a ser observado na avaliação Suassuna (2013) ressalta que a maior espessura do diâmetro do colmo pode ser útil para evitar acamamento das plantas na fase adulta devido a época de produção e aos efeitos dos ventos.

Araújo et al. (2014) em experimento utilizando soluções nutritivas e diferentes doses de fósforo obteve apenas ajuste para regressão linear $(p<0,01)$ e não foram encontrados os valores máximos de adubação para a variável diâmetro do colmo.

Valores médios iguais ao do experimento em relação ao diâmetro do colmo foram encontrados por Santos (2016) quando alcançou média de $1,59 \mathrm{~cm}$ na dose de $120 \%$ de adubação organomineral.

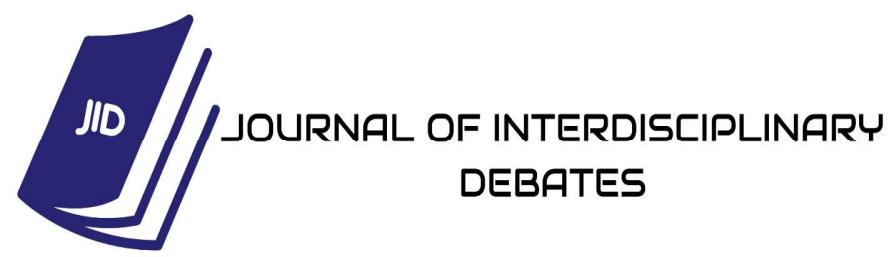


ISSN: $2675-469 \mathrm{X}$

Vol. 02 - n 04 - ano 2021

Editora Acadêmica Periodicojs

Gráfico 1. Análise de regressão para o diâmetro do colmo - D e de comprimento da vagem - C para a variação das doses de fósforo.

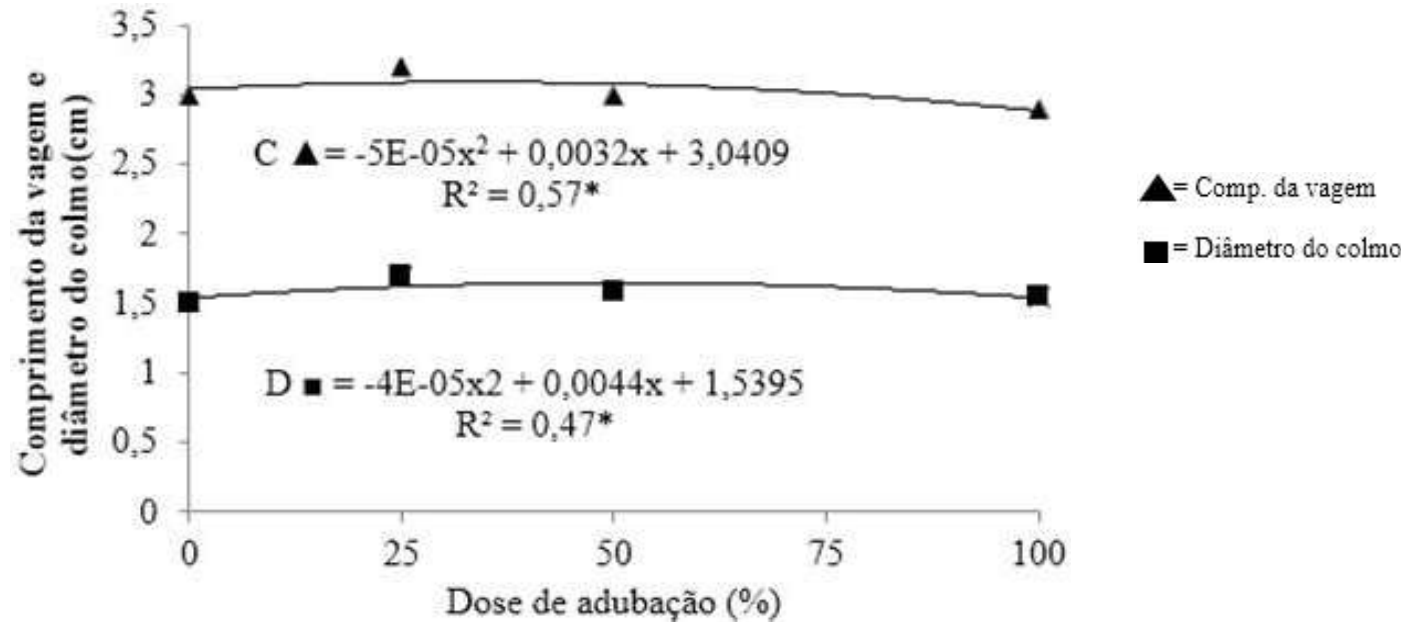

Por meio de identifica- (1989) devido a esse nutriente ser ção visual, Araújo et al. (2014) essencial e altamente móvel na verificaram que as plantas de planta, tais características podem gergelim da variedade BRS Seda ser sintomas de deficiência de cultivadas na ausência de fósforo fósforo, uma vez que a carência apresentou características como: deste elemento induz a utilização tamanho inferior das demais, de P não metabolizado das folhas caule descolorido, clorose gene- mais velhas, sendo redistribuído ralizada com bordas necróticas para os órgãos mais novos, que nas folhas mais velhas e folhas cessa seu crescimento quando tal jovens apresentando coloração reserva acaba.

verde opaca e levemente murEm condições de camchas, além de raízes com sinais po, as plantas com deficiência de de necrose. fósforo podem exibir sintomas Segundo Malavolta parecidos como folhas adultas 
ISSN: 2675-469X

Vol. 02 - n 04 - ano 2021

Editora Acadêmica Periodicojs

apresentando coloração verde escura e folhas jovens com coloração verde-cinzenta e bordas necrosadas (BELTRÃO et al 2001b).

Para o PhosphoBavar-2 houve diferença significativa $(\mathrm{p}<0,05)$ nas três variáveis analisadas (tabela 3), com melhores resultados para as plantas que foram inoculadas com bactérias do gênero Pseudomonas. Diferentemente, Zucareli et al. (2011) analisando a produtividade do milho com base na inoculação de $P$. flourescens não obteve respostas significativa para as variáveis alturas das plantas e comprimento das espigas. Trabalhos realizados posteriormente por Chaves et al. (2013) e Oliveira et al. (2015) com a cultura do milho e com inoculação de P. flourescens não obtiveram resultados para as variáveis altura das plantas e diâmetro do colmo.
Observa-se na Tabela 4

que os coeficientes de variação obtiveram valores médios para as variáveis $n^{0}$ de vagem por planta e $n^{\circ}$ de grãos por vagem e valores baixos para a variável massa de 1000 grãos com base na classificação de Pimentel Gomes (2009).

Na tabela 4, verifica-se que a análise de variância não apresentou diferença significativa para a interação entre adubação e Phosphobarvar-2 para as variáveis $\mathrm{n}^{\mathrm{o}}$ de vagem por planta, número de grãos por vagem e massa de 1000 grãos.

Analisando separadamente, nota-se que apenas o $\mathrm{n}^{\mathrm{o}}$ de vagens por planta foi significativo, apresentando diferença significativa a $1 \%$ de probabilidade para a adubação e $5 \%$ para o Phosphobarvar. 
ISSN: $2675-469 X$

Vol. 02 - n 04 - ano 2021

Editora Acadêmica Periodicojs

TABELA 4. Síntese da análise de variância para o número de vagens por planta $\left(\mathrm{N}^{\circ}\right.$ Vagens/planta), o número de grãos por vagem (Número grãos/vagem) e damassa de 1000 grãos, e do teste de médias para o fator PhosphoBarvar-2.

\begin{tabular}{ccccc}
\hline & & \multicolumn{3}{c}{ Valores de F } \\
\cline { 3 - 5 } Fontes de Variação & G.L. & $\mathrm{N}^{\circ}$ Vagens/planta & $\begin{array}{c}\text { Número } \\
\text { grãos/vagem }\end{array}$ & Massa 1000 grãos \\
\hline Bloco & 2 & $1,43^{\mathrm{NS}}$ & $2,86^{\mathrm{NS}}$ & $0,31^{\mathrm{NS}}$ \\
Adubação (A) & 3 & $11,59^{* *}$ & $3,67^{\mathrm{NS}}$ & $3,38^{\mathrm{NS}}$ \\
Resíduo 1 & 6 & - & - & - \\
PhosphoBarvar (P) & 1 & $3,98^{*}$ & $0,01^{\mathrm{NS}}$ & $0,16^{\mathrm{NS}}$ \\
Interação A*P & 3 & $0,91^{\mathrm{NS}}$ & $2,05^{\mathrm{NS}}$ & $1,93^{\mathrm{NS}}$ \\
Resíduo 2 & 8 & - & - & - \\
\hline CV 1 (\%) & - & 12,03 & 11,99 & 5,47 \\
CV 2 (\%) & - & 14,58 & 15,36 & 3,93 \\
Média Geral & - & 168 vagens & 62,6 grãos & $3,67 \mathrm{~g}$ \\
\hline
\end{tabular}

Teste de Médias de Tukey $(\mathrm{p}<0,05)$

Fatores

No Vagens/planta $\begin{gathered}\text { Número } \\ \text { grãos/vagem }\end{gathered}$ Massa 1000 grãos

unidade planta $^{-1}$

G

PhosphoBarvar-2 (P) -

$\begin{array}{lllll}\text { Com } & - & 178 \mathrm{a} & 62,5 \mathrm{a} & 3,68 \mathrm{a} \\ \text { Sem } & - & 157 \mathrm{~b} & 62,6 \mathrm{a} & 3,66 \mathrm{a}\end{array}$

Médias seguidas pela mesma letra minúscula na coluna, não diferem entre si pelo teste de Tukey a 5\% de probabilidade.

**: significativo $(\mathrm{P}<0,01)$; *: significativo $(\mathrm{P}<0,05)$; NS: não significativo; $C V \%$ : coeficiente de variação.

Para o número de va- comendada para o fósforo. Vasgem por planta, a análise de re- concelos et al. (2010) afirma que gressão para as doses de fósforo a quantidade de vagem está direapresentou diferenças estatísticas tamente relacionada com a proa 1\% de significância (Gráfico 2) dutividade da cultura, sendo que apresentando resposta quadrática quanto maior a quantidade de vae com ponto de máximo estima- gens, maior será a quantidade de do em 195,9 vagem por planta sementes, e consequentemente a com uma dose de $51,78 \%$ da re- produtividade.

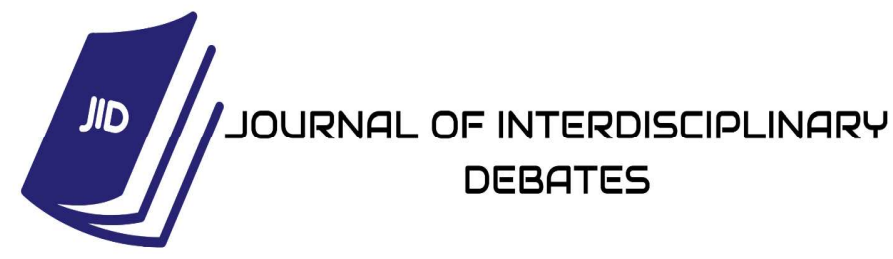


ISSN: $2675-469 \mathrm{X}$

Vol. 02 - n 04 - ano 2021

Editora Acadêmica Periodicojs

Gráfico 2 - Análise de regressão para o número de vagens por planta

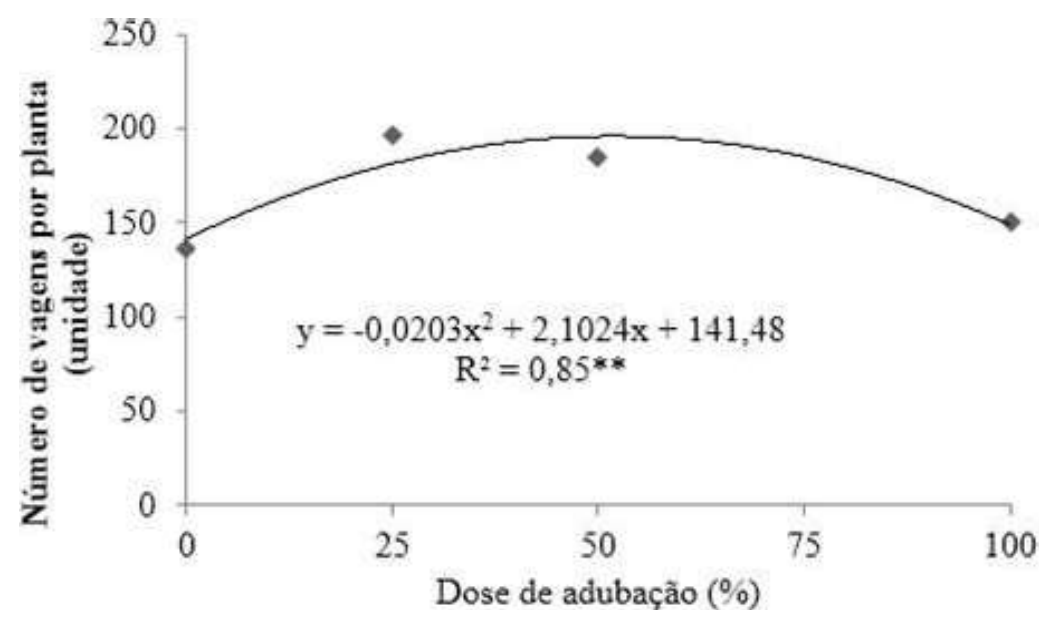

Segundo Carneiro et al. do resposta quadrática significa(2016), ainda é limitado o númetiva a $5 \%$. Para o peso de 1000 ro de estudos sobre o número de sementes os resultados do trabagrãos por vagem na cultura do lho apresentaram resposta linear gergelim, pois a mesma varia de significativa a $5 \%$ com um auacordo com as cultivares. Porém, mento de $14 \%$ comparado com a em estudos realizados com difetestemunha e peso de $3,20 \mathrm{~g}$ na rentes doses de fósforo no sul do máxima dose aplicada.

estado do Tocantins, obteve resObserva-se na tabela 5 posta linear para a quantidade de que os coeficientes de variação vagem por planta e um aumento para a produtividade das vagens de $47 \%$ no número de vagens em e produção de grãos apresenrelação a testemunha na cultura tam valores médios com base na do gergelim. Outro fator que teve classificação de Pimentel Gomes significância foi a quantidade de (2009) e os valores para variável sementes por vagem apresentanrendimento apresentam valores

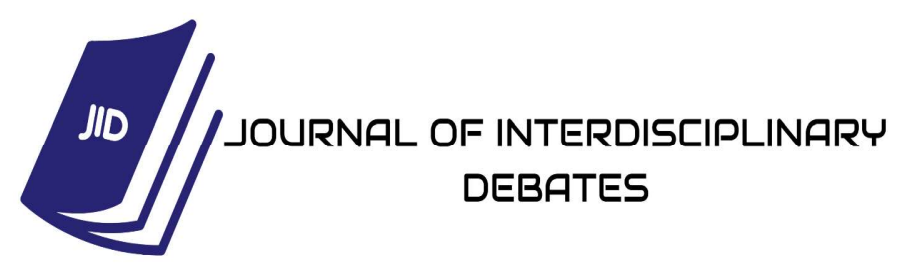


ISSN: 2675-469X

Vol. 02 - n 04 - ano 2021

Editora Acadêmica Periodicojs

baixos com base na mesma classificação.

Assim como nas tabelas anteriores, a interação entre os fatores adubação e PhosphoBavar-2 não apresentou diferença significativa para os dados de produtividade de vagens, produção de grãos e rendimento como mostra na Tabela 5.

Meneghette et al. (2017) no experimento sobre doses de fósforo e potássio em plantas de amendoim na presença e ausência de adubação foliar obtiveram resultados semelhantes em relação ao rendimento pois os tratamentos não proporcionaram diferenças significativa.

Avaliando o PhosphoBarvar-2, observa-se que apenas o rendimento de grãos não foi significativo e apresentou valores iguais a média geral foi de $57 \%$. A produtividade de vagens e de grãos foram significativas a 5\%, tendo um aumento de 278 e 143

kg ha ${ }^{-1}$, respectivamente. Costa (2015) avaliando a produtividade de quatro genótipos de gergelim obteve valores superiores para a produtividade de grãos, com a aplicação do bioestimulante Stimulate $\AA$.

Para a adubação, as variáveis produtividade de vagens e produtividade de grãos apresentaram diferença significativa a $1 \%$ e o rendimento não apresentou significância. 
ISSN: $2675-469 \mathrm{X}$

Vol. 02 - n 04 - ano 2021

Editora Acadêmica Periodicojs

TABELA 5. Síntese da análise de variância para a produtividade de vagens (Prod. Vagens), a produtividade de grãos (Prod. Grãos) e para o rendimento de grãos (Rendimento), e do teste de médias para o fator PhosphoBarvar-2.

\begin{tabular}{ccccc}
\hline \multirow{2}{*}{ Fontes de Variação } & G.L. & \multicolumn{3}{c}{ Valores de F } \\
\cline { 3 - 5 } & 2 & Prod. Vagens & Prod. Grãos & Rendimento \\
\hline Bloco & $3,88^{\mathrm{NS}}$ & $3,36^{\mathrm{NS}}$ & $0,92^{\mathrm{NS}}$ \\
Adubação (A) & 3 & $10,11^{* *}$ & $10,75^{* *}$ & $1,61^{\mathrm{NS}}$ \\
Resíduo 1 & 6 & - & - & - \\
PhosphoBarvar-P & 1 & $6,34^{*}$ & $4,97^{*}$ & $0,74^{\mathrm{NS}}$ \\
Interação A*P & 3 & $1,02^{\mathrm{NS}}$ & $0,97^{\mathrm{NS}}$ & $2,69^{\mathrm{NS}}$ \\
Resíduo 2 & 8 & - & - & - \\
\hline CV 1 (\%) & - & 12,34 & 13,68 & 5,14 \\
CV 2 (\%) & - & 15,88 & 16,16 & 3,68 \\
Média Geral & - & $3.398 \mathrm{~kg} \mathrm{ha}^{-1}$ & $1.958 \mathrm{~kg} \mathrm{ha}^{-1}$ & $57,50 \%$ \\
\hline
\end{tabular}

Teste de Médias de Tukey $(\mathrm{p}<0,05)$

Fatores - Prod. Vagens Prod. Grãos Rendimento

\begin{tabular}{|c|c|c|c|c|}
\hline & & ---------- & ----------- & $\%$ \\
\hline PhosphoBarvar (P) & - & & & \\
\hline Com & - & $3.676 \mathrm{a}$ & $2.101 \mathrm{a}$ & 57,1 a \\
\hline Sem & - & $3.121 \mathrm{~b}$ & $1.813 \mathrm{~b}$ & $57,8 \mathrm{a}$ \\
\hline
\end{tabular}

Médias seguidas pela mesma letra minúscula na coluna, não diferem entre si pelo teste de Tukey a 5\% de probabilidade.

**: significativo $(\mathrm{P}<0,01)$; *: significativo $(\mathrm{P}<0,05)$; NS: não significativo; CV\%: coeficiente de variação.

Com relação a aduba- dose de 43,34\% de fósforo para a ção, obteve-se uma regressão produtividade de grãos.

polinomial de segunda ordem Melo et al. (2013) obsignificativo $(\mathrm{p}<0,01)$ para as va- tiveram efeitos significativos riáveis produtividade de vagens e $\quad(\mathrm{p}<0,05)$ para a produtividade de produtividade de grãos (Gráfico grãos de feijão caupi em relação 3), tendo pontos de máximo com às doses de fósforo respondendo valores de $3.830 \mathrm{~kg}$ ha-1 para a de maneira quadrática com a prodose de $45,05 \%$ de fósforo para a dução de $1.257 \mathrm{~kg} \mathrm{ha}^{-1}$ na dose de produtividade de vagens e valor $50 \mathrm{~kg}$ ha-1 de $\mathrm{P} 2 \mathrm{O} 5$. máximo de $2.210 \mathrm{~kg} \mathrm{ha}^{-1}$ para a Diferentemente destes 
ISSN: $2675-469 \mathrm{X}$

Vol. 02 - n 04 - ano 2021

Editora Acadêmica Periodicojs

resultados, Zucareli et al. (2006) cultivar IAC Carioca em função

em trabalho realizado não encon- da adubação fosfatada.

trou resposta significativa para a

produção de grãos de feijão da

Gráfico 3 - Análise de regressão para PV-produtividade das vagens e PG- produtividade de grãos

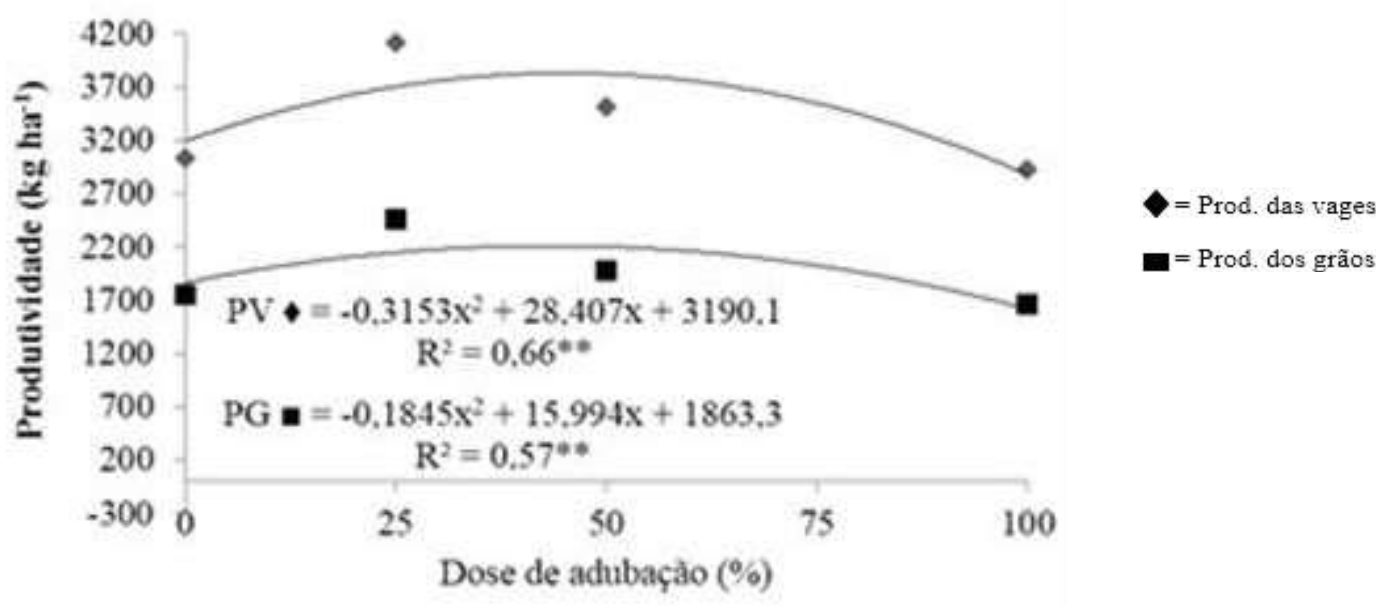

Segundo Araújo (2005) (PhosphoBARVAR-2) apreseno fósforo deve estar na forma dis- tou um aumento de $278 \mathrm{~kg}$ ha- 1 ponível e absorvível pelas plan- para a produtividade de vagens e tas, o que irá proporcionar maior $\quad$ de $143 \mathrm{~kg} \mathrm{ha}^{-1}$ para a produtividadesenvolvimento e produção à de de grãos. cultura.

As doses de fósforo apresentaram valor máximo de

\section{CONCLUSÕES}

A inoculação com as bactérias Pseudomonas Putida e Pantoea Agglomerans do produto
$3.830 \mathrm{~kg} \mathrm{ha}^{-1}$ de vagens na dose de $45,05 \%$ da recomendada e $2.210 \mathrm{~kg} \mathrm{ha}^{-1}$ de grãos na dose de $43,34 \%$.

Contudo é necessários

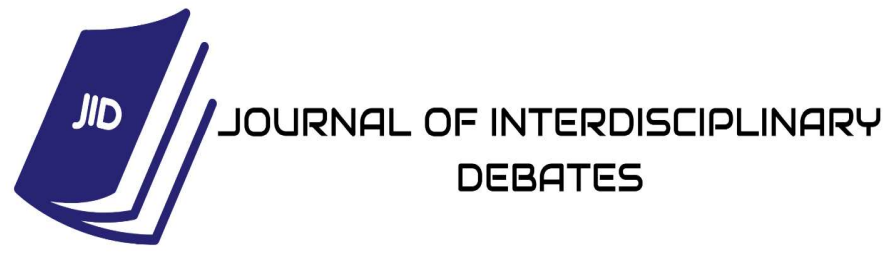


ISSN: $2675-469 \mathrm{X}$

Vol. 02 - n 04 - ano 2021

Editora Acadêmica Periodicojs

novos experimentos de pesquisa uma vez que estudos com a cultura ainda são escassos e com o intuito de comprovar o benefício tanto da utilização de bactérias como na utilização do fósforo.

\section{REFERÊNCIAS}

AERTS, R. Nutrient resorpiton from senescing leaves of perennials: ARE THERE GENERAL PATTERNS? Journal Ecology, v. 84, p. 597-608, 1996.

ALVARES, C. A.; STAPE, J. L.; SENTELHAS, P. C.; GONÇALVES, J. L. M.; SPAROVEK, G. Koöppen's climate classification map for brazil. Meteorologische Zeitschrift, Berlim, v. 22, n. 6, p. 711-728, 2013.

ALVES, L. de S. Crescimento e produtividade do gergelim sob fontes e doses de matéria orgâni- ca. 2014. 49p. Dissertação (Mestrado em Sistemas Agroindustriais) - Universidade Federal de Campina Grande. Pombal, PB, 2014.

ARAÚJO, A. P.; MACHADO, C. T. T. Fósforo. In: Nutrição Mineral de Plantas. Sociedade Brasileira de Ciência do Solo. Viçosa. MG. 1 Ed, p. 253-273, 2006.

ARAÚJO, E. N. Rendimento do pimentão (Capsicum annuum L.) adubado com esterco bovino e biofertilizante. 2005. 98 p. Dissertação (Mestrado em Agronomia). Universidade Federal da Paraíba, Areia-PB, 2005.

ARAÚJO, F. dos S.; BORGES, S. R. dos S.; SILVA, G. Z.; ARAÚJO, L. H. B.; TORRES, E. J. de M. Doses de fósforo no crescimento inicial do gergelim cultivado em solução nutritiva. Tec- 
Vol. 02 - n 04 - ano 2021

Editora Acadêmica Periodicojs

nologia e Ciências Agropecuária, Brasília: Embrapa Informação

João Pessoa, v. 8, n.2, p.41-47, Tecnológica, 2001b. 348p.

Jun, 2014.

BERBARA， R.L.L.; SOUZA， BELTRÃO, N,. E. de M.; NÓ- $\quad$ F.A.; FONSECA, H.M.A.C. FunBREGA, L. B. da SOUZA, R. P. gos micorrízicos arbusculares: de; SOUZA, J. E. G. de, Efeitos muito além da nutrição. In: FERda adubação, configuração de NANDES, M.S. Nutrição mineplantio e cultivares na cultura do ral de plantas. Viçosa: Sociedade gergelim no nordeste do Brasil, Brasileira de Ciência do Solo, Campina Grande: Embrapa Al- 2006. p. 53-88.

godão PA. (Embrapa Algodão, Boletim de Pesquisa, 21), 23p. 1989.

BEZERRA, S. A.; NETO, J. D.; de AZEVEDO, C. A. V.; SILVA, M. B. R.; SILVA, M. M. ProduBELTRÃO, N. E. de M.; VIEIção do gergelim cultivado sob RA, D. J. O agronegócio do ger- condições de estresse hídrico e gelim no Brasil. Brasília: EM- diferentes doses de adubação. BRAPA/CNPA, 2001. p. 18-27. Engenharia Ambiental - Espírito Santo do Pinhal, v. 7, n. 3, p. 156 BELTRÃO, N. E. M.; SILVA, L. - -165, jul. /set. 2010.

C.; QUEIROGA, V. P.; VIERA, D. J. Preparo do solo, adubação e calagem. In: BELTRÃO, N. E. de M.; VIEIRA, D. J. (Org.) O agronegócio do gergelim no Brasil.

BIELESKI, R. L. Phosphate pools, phosphate transport, and phosphate availability. Annual Review of Plant Physiology, v. 
Vol. 02 - n 04 - ano 2021

Editora Acadêmica Periodicojs

24, p. 225-252, 1973.

CARNEIRO, J. S. da S.; SILVA, P. S. S.; FREITAS, G. A.; SANTOS, A. C.; SILVA, R. R. Resposta do gergelim à adubação com esterco bovino e doses de fósforo no sul de Tocantins. Revista Scientia Agraria, vol. 17 n. 2 Curitiba abril/maio. 2016 p. 4148.

CHAVES, D. P.; ZUCARELI, C.; JUNIOR, ALISON de OLIVERIRA. Fontes de fósforo associadas à inoculação com Pseudomonas fluorescens no desenvolvimento e produtividade do milho. Ciências Agrárias, Londrina, v. 34, n. 1, p. 57-72, jan./fev. 2013.

COSTA, F. S.; GOMES, A.H.S.; FERREIRA，D.J.L.; CHAVES, L.H.G.; MAGALHÃES， I.D.; PINTO SOBRINHO, P.F. Crescimento e produção do gerge- lim irrigado em função da adubação potássica e nitrogenada. Workshop internacional de inovações tecnológicas na irrigação. Fortaleza, 2012.

Fertilizantes Orgânicos biológicos: NPK BIOLÓGICO - BARVAR-N， BARVAR-P， BARVAR-K, Green Biotech Brasil. Disponível em: < http://www. greenbiotech.com.br/> acesso 2018

COSTA, N. R.; ANDREOTTI, M.; SANTOS, F. G.; SOUZA, L. M. F.; CAVAlLinI, M. C. Interação entre inoculação das sementes com Pseudomonas fluorescens e adubação fosfatada na produção do milho em sucessão a espécies forrageiras no Cerrado. Tecnologia \& Ciência Agropecuária, João Pessoa,v.7, n.3, p.37-43, set. 2013.

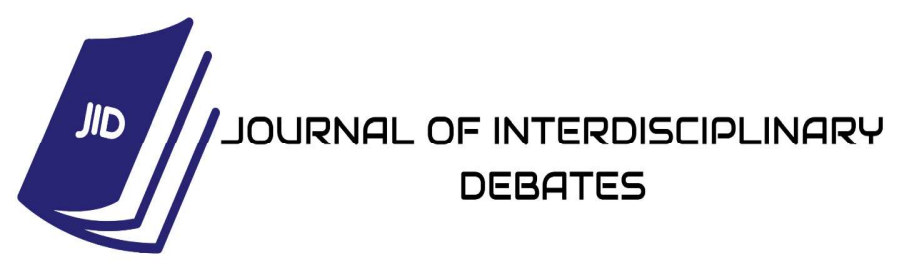


COSTA, D. S. Produtividade de genótipos de gergelim sob a influência de fitoestimulante. 2015. p 71 Dissertação (Mestrado em produção agrícola) - Universidade Federal Rural de Pernambuco) Garanhuns, PE 2015.

EMBRAPA - Empresa Brasileira de Pesquisa Agropecuária. BRS SEDA: Gergelim BRS Seda. Campina Grande: EMBRAPA-CNPA, 2007. 6p. (Folder). Disponível em: $<$ https://ainfo.cnptia. embrapa.br/digital/bitstream/ CNPA/20121/1/Folder_brs_seda. pdf $>$. Acesso em: 28 Set 2018

EMBRAPA - Empresa Brasileira de Pesquisa Agropecuária. Coleção Plantar: A cultura do Gergelim. 1. Ed. 2007b. p 21-23. Disponível em:< https://ainfo. cnptia.embrapa.br/digital/bitstream/item/11911/2/00080980.pdf>. Acesso em: 28 Set 2018.
EMBRAPA - Empresa Brasileira de Pesquisa Agropecuária. Tecnologias Utilizadas no Cultivo do Gergelim Mecanizado. 1. Ed. 2008. p 42-43. Disponível em:< https://www.infoteca.cnptia.embrapa.br/bitstream/doc/278027/1/ DOC203.pdf $>$. Acesso em 28 Set 2018.

EMBRAPA -EMPRESA BRASILEIRA DE PESQUISA AGROPECUÁRIA. Sistema de produção: Cultivo do Gergelim. 2. Ed. 2014. Disponível em: <https://www.spo.cnptia.embrapa. br/conteudo?p_p_id=conteudoportlet_WAR_sistemasdepro ducaolf6_1galceportlet\&p_p_lifecycle $=0 \& p \_p \_$state $=$nor mal\&p_p_mode $=v i e w \& p \_p$ col_id=column-1\&p_p_col_cou$\mathrm{nt}=1 \& \mathrm{p} \_$__p_-76293187_sistemaProducaoId=3714\&p_r_p_996514994_topicoId=3181>. 
Vol. 02 - n 04 - ano 2021

Editora Acadêmica Periodicojs

Acesso em: 28 Set 2018.

FRANDOLOSO, J. F. Eficiência

ELLIOTT, G. C.; LÄUCHLI, A. de adubos fosfatados associados Phosphorus efficiency and phos- a enxofre elementar na cultura phate-iron interactions in maize. do milho. 2006. 63p. Dissertação Agronomy Journal, v. 77, p. 399- (Mestrado em Agronomia) Uni403, 1985.

versidade Estadual do Oeste do Paraná, Marechal Cândido Ron-

FAO - Food and Agriculture don.

Organization of the United Nations. Statistical data. Disponível FUNCEME. Levantamento de em: http://faostat.fao.org/faostat. Acesso em 20 Set 2018.

reconhecimento de média intensidade dos solos da Mesoregião do Sul Cearense / Fundação Ce-

FERNANDES, M.S. Nutrição mineral de plantas. Viçosa: Sociedade Brasileira de Ciência do Solo, 2006. p. 254.

FEIL，B.; THIRAPHORN, R.; STAMP, P. Can maize cultivars with low mineral nutrient concentrations in the grains help to reduce the need for fertilizers in third world countries. Plant Soil, v. 146, p. 227-231, 1992. arense de Meteorologia e Recursos Hídricos. Fortaleza, 2012.

HAAG，H. P.; MALAVOLTA, E.; GARGANTINI, H.; BLANCO, H. G. Absorção de nutrientes pela cultura do feijoeiro. Bragantia, v. 26, p. 381-391, 1967.

KANNAN, S. Role of the foliar fertilization on plant nutrition. In: BALIGAR, V. C.; DUNCAN, 
R. R., eds. Crops as enhancers of nutrient use. San Diego, Academic Press, p. 313-348, 1990.

KOURI, J.; ARRIEL, N.H.C. 2006.

Aspectos Econômicos. In: AR-

RIEL, N.H.C.; BELTRÃO,

N.E.de M.; FIRMINO, P. de T.

Gergelim: o produtor pergunta, a

Embrapa responde. Brasília: Em-

brapa Informação Tecnológica, 2009. p.193-209.

LANGHAM, D.R.; WIEMERS,

T. Progress in mechanizing sesame in US through breeding In.: JANICK，J.; WHIPCKEY，A (Eds.) Trends in new crops and new uses. Alexandria VA: ASHS Press, 2002. p.157-173.

LAYANEZ-GARSABALL， J

MAIA FILHO, F. C. F.; MESQUITA, E. F.; MELO, D. S.; SOUSA, P. M.; PEREIRA, R. J. F; MELO, W. B.; VIEIRA, I. G. A.; MÉNDEZ-NATERA, J.R. M. Efectos de extractos acuosos del follaje del corocillo (Cyperus rotundus L.) sobre la germinaci-

S.; ANDRADE, R. Desenvolvimento fisiológico do gergelim BRS Seda sob cultivo orgânico. In: Simpósio Internacional De ón de semillas y el crecimiento de plántulas de ajonjolí (Sesamum indicum L.) cv. Arapatol S-15. Idesia, v. 24, n. 2, p. 61-75, LIMA, V. I. Crescimento e Produção de gergelim cv. G3 em função de zinco e boro. 2006. 72p. Dissertação (Mestrado em Agronomia) - Universidade Federal da Paraíba. Areia, PB, 2006.

LOUGHMAN, B. C. Metabolic aspects of the transport of ions by cells and tissues of roots. Plant Soil, v. 63, p. 47-55, 1981.

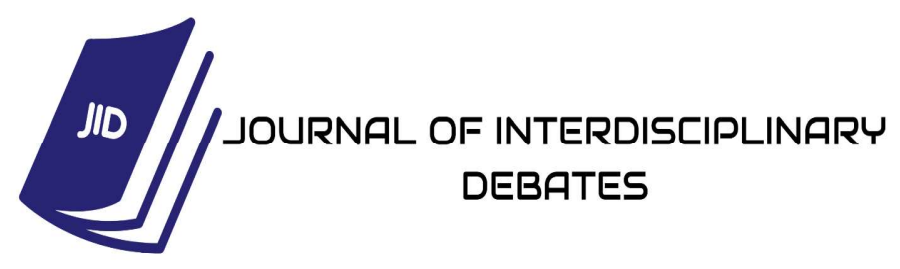


ISSN: 2675-469X

Vol. 02 - n 04 - ano 2021

Editora Acadêmica Periodicojs

Oleaginosas E Fibrosas, 1., 2010, Campina Grande. Anais... Campina Grande: Embrapa Algodão, 2010. p. 616-621.

MALAVOLTA, E. 1926-Elementos de Nutrição de Plantas. São Paulo: Ed. Agronômica Ceres LTDA, 1980. p. 131

MALAVOLTA, E. Abc da adubação. São Paulo: Agronômica Ceres, 1989. 304p.

MARCILIO, H. C.; RAMOS, M. J. M.; ANDRADE, A. L.; SILVA, E. C.S.; SANTOS,C. C. Efeito de biofertilizante no crescimento e na produção da bananeira 'farta velhaco', no Sudoeste de Mato Grosso. Revista Brasileira de Agropecuária Sustentável. v.4, n.2., p.131- 135, 2014.

MARSCHNER, H.; DELL, B Nutrient uptake in mycorrhizal symbiosis. Plant and Soil, v. 159, p.89-102, 1994.

MARSCHNER, H. Mineral nutrition of higher plants. London, Academic Press, p. 889, 1995.

MAZZANI, B. Cultivo y mejoramiento de plantas oleaginosas. Caracas: [s.n.], 1983. p. 169-226.

MELO, F. de B.; CARDOSO, M. J.; BASTOS, E. A.; RIBEIRO, V. Q. Resposta do Feijão-Caupi à adubação fosfatada e potássica em latossolo amarelo distrocoeso no cerrado do leste, III Congresso Nacional de Feijão-Caupi (2013), Recife - PE. Disponível em: < https://www.embrapa.br/busca-de-publicacoes/-/ publicacao/961129/resposta-do-feijao-caupi- a-adubacao-fosfatada-e-potassica-em-latossolo-amarelo-distrocoeso-no-cerrado-do-leste- maranhense>.

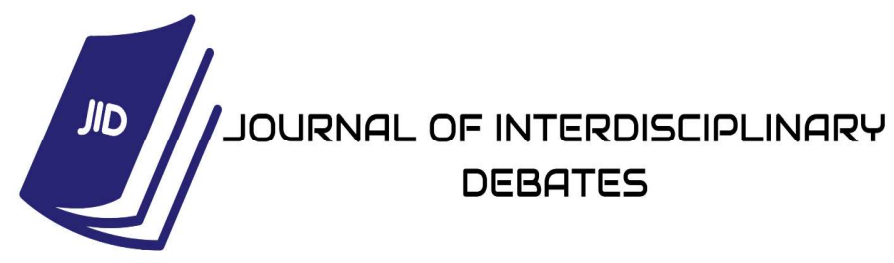


ISSN: 2675-469X

Vol. 02 - n 04 - ano 2021

Editora Acadêmica Periodicojs

Acesso em: 28 Set 2018.

ciedade Brasileira de Ciência do

solo, 1. Ed, p. 471-537, 2007.

MENEGHETTE， H.H.A.; LA-

ZARINI, E.; BOSSOLANI, J.W.;

OLIVEIRA, A.L.M.; URQUIA-

PARRA, L. F.; HAYASHI, F. K.

GA, S.; BALDANI, J.I. Proces-

Doses de fósforo e potássio em sos e mecanismos envolvidos na plantas de amendoim na presença e ausência de adubação foliar, Brazilian Journal of Biosystems Engineering, v. 11, n.2, p. 125134, 2017. influência de microrganismos sobre o crescimento vegetal. Seropédica: Embrapa Agrobiologia, 2003. 40p. (Embrapa Agrobiologia. Documentos, 161). 2003.

MOREIRA, F.M.S.; SIQUEIRA, OLIVEIRA, M. A.; ZUCARELI, J.O. Microbiologia e bioquímica C. FERREIRA, A. S.; DOMINdo solo. Lavras, Universidade Federal de Lavras, 2002, 626p.

GUES, A. R.; SPOLAOR, L. T.; NEVES, C. S. V. J. Adubação fosfatada associada à inoculação MOREIRA, F. M. S.; SIQUEIRA, J. O. Microbiologia e bioquímica do solo. 2. Ed. Lavras, Universidade Federal de Lavras, com Pseudomonas fluorescens no desempenho agronómico do milho. Revista de Ciências Agrárias, v.38, n.1, p. 18-25, 2015. 2006, 720p.

NOVAIS, R. F.; SMYTH, T. J.;

NUNES, F. N. Fósforo. In: Fertilidade do solo. Viçosa, MG: So-

PARNISKE, M. Arbuscular mycorrhiza: the mother of plant root endosymbioses. Nature Reviews Microbiology, v. 6, p. 763-775,

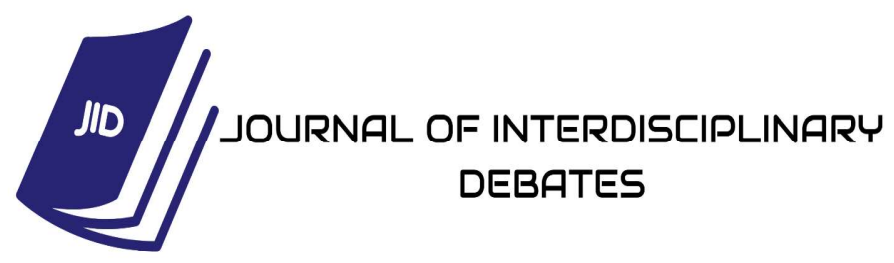


ISSN: $2675-469 X$

Vol. 02 - n 04 - ano 2021

Editora Acadêmica Periodicojs

2008

RAIJ, B. van; CANTARELLA,

PEREIRA, J. R.; BELTRÃO, N. H.; CAMARGO, A.P. \& SOA-

E. de M.; ARRIEL, H. C.; SILVA, RES,E. Perdas de cálcio e mag-

E. S. B da. Adubação orgânica nésio durante cinco anos em

do gergelim no seridó paraibano. ensaio de calagem. Revista Bra-

Revista brasileira de oleaginosas sileira de Ciência do Solo, v. 6, p.

fibrosas. Campina Grande.v. 6, 33-37, 1982.

n.2, p. 515-523, 2002.

RAVEN, P. H.; EVERT, R. F.;

PERIN, A.; CRUVIEL, D. J.; EICHHORN, S. E. Biologia ve-

SILVA, J. W. Desempenho do getal. 5.ed. Rio de Janeiro: Gua-

gergelim em função da adubação nabara Koogan S.A., 1996. 728p.

NPK e do nível de fertilidade do

solo. Acta Scientiarum. Agro-

RATZ, R. J., Uso de bactérias do nomy. Maringá. v. 32, n. 1, p. 9398,2010

gênero bacillus como promotoras de crescimento para a cultura do milho e da soja, Toledo, 2014.

PIMENTEL GOMES, F. Curso de estatística experimentel. 15. RICHARDSON, A.E. Prospects ed. Piracicaba: Fealq, 2009. 451p. for using soil microorganisms to improve the acquisition of phosRAGHOTHAMA, K. G. Phos- phorus by plants. Aust. J. Plant phate transport and signaling. Physiol, v.28, p.897-906, 2001. Current Opinion in Plant Biology, v. 3, p. 182-187, 2000.

RODRÍGUEZ, H. e FRAGA, R.

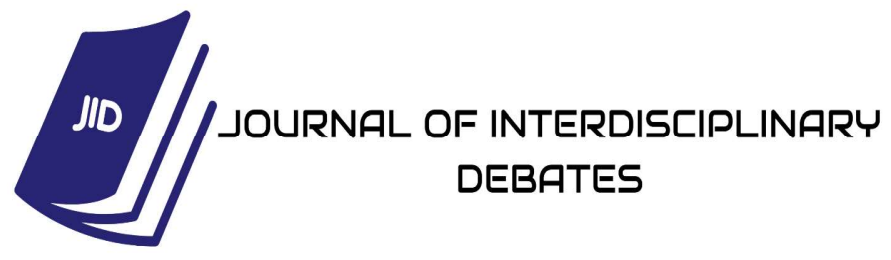


Vol. 02 - n 04 - ano 2021

Editora Acadêmica Periodicojs

(1999) - Phosphate solubilizing

bacteria and their role in plant

growth promotion. Biotechnology Advances, v. 17, n. 4-5, p. 319339.

SANTOS, SAINT-CLEAR. S.

Crescimento, fisiologia e produção de genótipos de gergelim sob níveis de adubação organomineral. 2016. 78p. Dissertação (Programa de Pós- Graduação em Ciências Agrárias) - Universidade Estadual da Paraíba / Embrapa Algodão. CAMPINA GRANDE, PB, 2016.

SCHACHTMAN, D. P.; REID, R. J.; AYLING, S. M. Phosphorus uptake by plants: From soil to cell. Plant Physiology, v. 116, p. 447-453, 1998.

SENTENAC, H.; GRIGNON, C. Effect of $\mathrm{pH}$ on orthophosphate uptake by corn roots. Plant Phy- siology, v. 77, p. 136-141, 1985.

SHUMAN, L. M. Mineral nutrition. In: WILKINSON, R. E., ed. Plant-environment interactions. New York, Marcel Dekker, p. 149-182, 1994.

SILVA, A. J. Efeito residual das adubações orgânica e mineral na cultura do gergelim(Sesamum indicum L.) em segundo ano de cultivo. 2006. 61p. Dissertação Universidade Federal da Paraíba. Areia - PB.

SILVA, E. L. G.; GONÇALVES, S. B.; FILHO, A. F. M.; ARRIEL, N. H. C.; de QUEIROZ, M. F. Crescimento e produção do gergelim em diferentes níveis de solução orgaomineral. Revista Verde de Agroecologia e Desenvolvimento Sustentável, V.11, $\mathrm{n}^{\mathrm{0}}$ 3, p. 33-38, 2016. 
ISSN: $2675-469 X$

Vol. 02 - n 04 - ano 2021

Editora Acadêmica Periodicojs

SOUZA, L. R.; PERES, F. S. B.

Uso de biofertilizantes à base de aminoácidos na produção de mudas de Eucalyptus dunnii. Pesquisa Florestal Brasileira. v. 6, n.87, p.211-218, 2016.

STEVENSON, F. J.; COLE, M. A. Cycles of soil carbon, nitrogen, phosphorus, sulfur, micronutrients. 2. Ed. New York, Wiley \& Sons, p. 427, 1999.

STEVENSON, F. J. Cycles of soil: carbon, nitrogen, phosphorus, sulfur, micronutrients. New York: John Wiley, p. 380, 1986.

SUASSUNA, J.F. Tolerância de genótipos de gergelim ao estresse salino. Campina Grande, 2013. 181p. Tese (Doutorado em Engenharia Agrícola) - Centro de Tecnologia e Recursos Naturais, Universidade Federal de Campina Grande.
THORNE, G. N. Factors effecting uptake of radioactive phosphorus by leaves and its translocations to other parts of the plant. Ann. Bot., v. 22, p. 381-398, 1958.

VANCE, C. P.; UHDE-STONE, C.; ALlEN, D. L. Phosphorus acquisition and use: Critical adaptations by plants for securing a nonrenewable resource. New Phytologist, v. 157, p. 423447, 2003.

VERGÜTZ, L.; NOVAIS, R. F. Recomendação de corretivos e adubação. In: Milho do plantio à colheita, 22. Ed. Viçosa, MG:

VASCONCELOS, R.A.; GONDIM, T.M.S.; ARRIEL, N.H.C. Características Vegetativas e Reprodutivas de Genótipos de Gergelim no Cariri Cearense. In:

\section{IID}


Vol. 02 - n 04 - ano 2021

Editora Acadêmica Periodicojs

IV Congresso Brasileiro de Mamona \& I Simpósio Internacional de Oleaginosas Energéticas, João Pessoa-PB, 2010. Anais. Campina grande: Embrapa Algodão, 2010, p. 1599-1605.

ZAIDI, A. e MOHAMMAD, S. (2006) - Co-inoculation effects of phosphate solubilizing microorganisms and glomus fasciculatum on green gram-bradyrhizobium symbiosis. Turkish Journal of Agriculture and Forestry, vol. 30, n. 3, p. 223-230.

ZUCARELI, C.; Cil, I.R.; PRETE, C.E.C. e PRANDO, A.M. (2011) - Eficiência agronômica da inoculação à base de Pseudomonas fluorescens na cultura do milho. Revista Agrarian, vol.4, n. 13, p. 152-157.

ZUCARELI, C.; ULISSES, E. R. J.; PACHECO, A. B.; NAKA-
GAW, J.; CAVARIANI, C. Adubação fosfatada, componentes de produção, produtividade e qualidade fisiológica em sementes de feijão, Revista Brasileira de Sementes, v.28, n.1, p.09-15, 2006.$$
\begin{gathered}
\text { IID JOURNAL OF INTERDISCIPLINARY } \\
\text { DEBATES }
\end{gathered}
$$ 